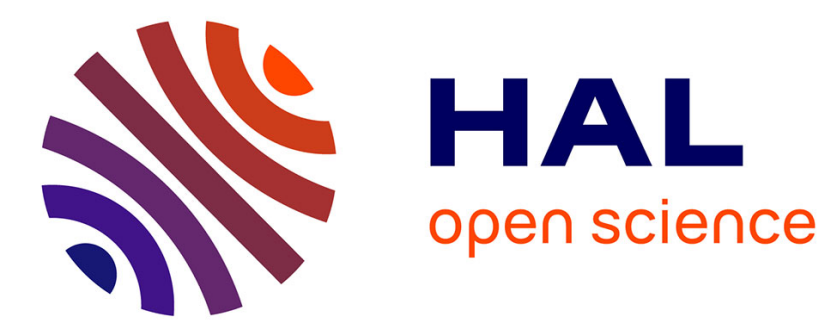

\title{
Nano-imprint lithography processing of inorganic-based materials
}

Mehrnaz Modaresialam, Zeinab Chehadi, Thomas Bottein, Marco Abbarchi

\section{To cite this version:}

Mehrnaz Modaresialam, Zeinab Chehadi, Thomas Bottein, Marco Abbarchi. Nanoimprint lithography processing of inorganic-based materials. Chemistry of Materials, 2021, 10.1021/acs.chemmater.1c00693 . hal-03328121

\section{HAL Id: hal-03328121 \\ https://hal.science/hal-03328121}

Submitted on 28 Aug 2021

HAL is a multi-disciplinary open access archive for the deposit and dissemination of scientific research documents, whether they are published or not. The documents may come from teaching and research institutions in France or abroad, or from public or private research centers.
L'archive ouverte pluridisciplinaire HAL, est destinée au dépôt et à la diffusion de documents scientifiques de niveau recherche, publiés ou non, émanant des établissements d'enseignement et de recherche français ou étrangers, des laboratoires publics ou privés. 


\title{
Nano-imprint lithography processing of inorganic-based materials
}

\author{
Mehrnaz Modaresialam, ${ }^{I}$ Zeinab Chehadi, ${ }^{I}$ Thomas Bottein,${ }^{I}$ Marco Abbarchi, ${ }^{1}$ \\ David Grosso. ${ }^{1 *}$ \\ ${ }^{1}$ Aix-Marseille Université, CNRS, IM2NP UMR 7334, Campus de St. Jérôme, 13397 Marseille, \\ France. \\ Corresponding author: david.grosso@univ-amu.fr
}

\begin{abstract}
We review past and recent progress in Nano-Imprint Lithography (NIL) methods to (nano-) structure inorganic materials from sol-gel liquid formulations and colloidal suspensions onto a surface. This technique, first inspired by embossing techniques, was developed for soft polymer processing, as final or intermediate materials, but is today fully adapted to hard inorganic materials with high dielectric constant, such as metal oxides, with countless chemical compositions provided by the sol-gel chemistry. Consequently, NIL has become a versatile, high throughput, and highly precise microfabrication method that is mature for lab developments and scaling up. We first describe the state-of-the-art in nanofabrication methods and the plethora of approaches developed in the last decades to imprint metal oxides from inorganic solutions. These are discussed and compared in terms of performances, issues, and ease of implementation. The final part is devoted to relevant applications in domains of interest.
\end{abstract}

\section{Generalities on Nano fabrication techniques and NIL}

From the early ages, technics to cut, sculpt, etch, mold, assemble pieces of matter have been developed and constantly optimized to satisfy the growing demand for functional materials. Since the inception of nanotechnology, these operations have to be mastered at the nanoscale. For these tasks, many top-down and bottom-up methods exist. However, they do not simultaneously fulfill all the necessary criteria of performance such as spatial resolution, pattern complexity, hierarchy, scalability, dimensionality, costeffectiveness, a span of processable materials. Thus, motivations to optimize them and develop new ones persist as a flourishing domain of research and development.

Many materials exhibiting various intrinsic properties (mechanical, chemical, electrical, optical, thermal, etc.) are exploited in numberless functions once nanostructured onto a surface. Amongst them, metal oxides are extremely valuable for their extreme chemical, mechanical and thermal stability and range of physicalchemical properties. Thanks to its hardness, chemical inertness, transparency and low background fluorescence, glass is one of the preferred choices for micro- and nano-fluidics device fabrication. In photonics, metasurfaces require optical properties that are found in dielectrics such as $\mathrm{SiO}_{2}$ often combined with high index dielectric $\mathrm{TiO}_{2}$ or (plasmonic) gold ${ }^{1}$. For nano-electronics, silica remains one of the key 
dielectric materials. Micro-mechanical scaffolds or persistent data storage systems need extremely stable materials such as $\mathrm{TiO}_{2}^{2}$.

For planar nanofabrication, either bottom-up (self-assembly) or top-down (lithography, etching) methods exist. First, bottom-up nano-structuration approaches based on micellar block copolymers self-assembly have shown great successes during the last decade ${ }^{3,4,5}$. A large variety of templating agents can be coupled with inorganic polymerization reactions for the design of periodically organized nanostructured metal-oxide hybrid phases ${ }^{6,7}$. Achievable periods and/or feature dimensions ranging from several nanometers to several tens of nanometers. However, the patterns adopt a periodical arrangement and exhibit many defects, no spatial control (position and direction), and poor long-range ordering limiting their applications. Amongst the top technological achievements of the last century in nanofabrication, photon-assisted processing methods are with no doubt the more technologically advanced ones. Photolithography combined with dry or wet etching of the hard metal oxides is today available with acceptable performances in terms of quality, versatility, resolution, throughput, cost, and achievable morphologies ${ }^{8,9,10,11}$. Still, these methods remain cumbersome and are constrained by a limited choice of required photosensitive selective masks, containing complex organic radical or cationic non-linear absorbers (photo-initiators) which are expensive, often colored, poorly soluble in photopolymers, and could be toxic ${ }^{12}$. Furthermore, photolithography faces an intrinsic critical limitation in resolution dictated by the wavelength of incident writing light waves (highenergy ultraviolet radiation (deep-UV) is used nowadays in production lines to elaborate features smaller than $40 \mathrm{~nm}^{13}$ ). Besides, these methods require hard-masks that need to be prepared by cumbersome Electron Beam Lithography (EBL), or Focused Ions Beam (FIB) ${ }^{14}$. Subtractive techniques involving laser/material interactions sharing similar non-linear optical effects but at much higher powers, are also available and are used to etch dense metal oxide surfaces. This approach has the advantage of ablating hard transparent materials such as glass beyond the diffraction limit, well into the nanoscale domain ${ }^{15},{ }^{16}$, but with poor axial resolution ${ }^{17}$.

Therefore, the alternative Nano Imprint Lithography method applicable to a large number of materials is extremely appealing as a reason of its high performance associated with its ease of implementation. The first work on nano-imprint lithography (NIL) was developed by Stephen Chou and al. in the 1990s when its team reported $25 \mathrm{~nm}$ patterns, initially etched in a silicon mold, transferred in a polymeric resist ${ }^{18}$. This experiment was performed by strongly pressing the mold ( $\mathrm{P}=50-100$ bars) while heating at $100{ }^{\circ} \mathrm{C}$ to deform and shape the thermoplastic polymer. This study opened the way to lithography at the sub-resist $100 \mathrm{~nm}$ scale. Imprinting of sol-gel resists was first demonstrated by Lukosz and al. in the 1980s at high pressure $(\mathrm{P}=280-500$ bars $)$ through hot embossing ${ }^{19}$. Even if the pressure used to imprint the sol-gel resist was rapidly reduced, it still represented one of the major drawbacks of this technique. Indeed, silicon substrates used in microelectronics can easily break if the applied pressure is not perfectly homogeneous. The use of hard and brittle molds (mostly silicon or fused silica) presented several downsides: (i) resist often sticks to the mold surface due to its high surface energy (ii) long-range deformation can easily break the mold (iii) solvent and air bubbles cannot escape once trapped under the mold (iv) rigid molds cannot accommodate any curvature or defects. Due to all those limitations, costly hard molds could be used only a very limited number of times. The emergence of Soft Nano Imprint Lithography (Figure 1), first developed by Whitesides et al. in the 1990s, tackled all those problems by the introduction of polydimethylsiloxane (PDMS) elastomeric molds ${ }^{20}$. Soft molds have low surface energy ( $\mathrm{P} P \mathrm{PDS}=21 \mathrm{~mJ} \cdot \mathrm{m}^{-2}$ compared to $\mathrm{y} \mathrm{Si}=52 \mathrm{~mJ} \cdot \mathrm{m}^{-2}$ ), are permeable to solvent vapors, and can deform to follow the features of the substrate. PDMS is inexpensive and each mold can be used dozen times. Soft-NIL allowed to drastically reduce the pressure ( $\mathrm{P}<5$ bars) and temperature applied to emboss the resist layer. With the huge improvements made in the past decades, Soft-NIL is 
currently performed at ambient pressure and room temperature and is now reaching sub-10 nm resolution ${ }^{21}$ on sol-gel resists when performed with optimized PDMS molds.

Stamp mold

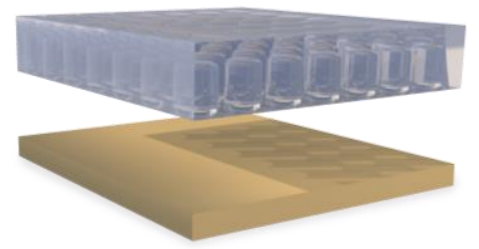

Thin Film

\section{Imprint and consolidation}

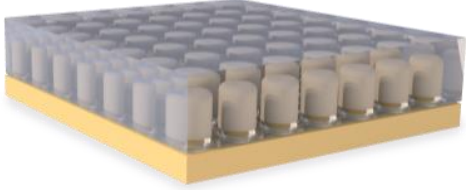

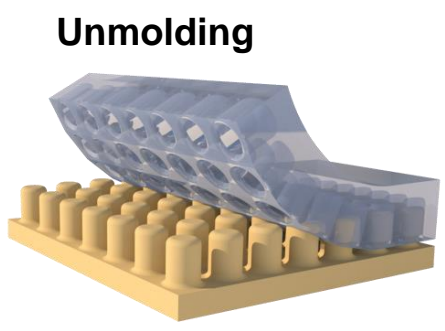

Figure 1. Schematic illustration of soft-NIL processing

The fabrication of the molds is performed by using a prepolymer - generally composed of vinyl functionalized linear di-methyl- siloxane and a silicon-hydride functionalized linear di-methyl-siloxane mixed with a catalyst - generally a platinum compound - and poured onto a pre-patterned surface. The crosslinking reaction, called hydrosilylation, is catalyzed by platinum and involves the addition of Si-H bonds across unsaturated bonds. The transition of the prepolymer from a viscous liquid to a solid elastomer takes usually several hours at room temperature. It is generally accelerated by heating at a mild temperature for instance $70{ }^{\circ} \mathrm{C}$. The hydrosilylation cross-linking route is generally preferred as no by-products are formed and it offers a comfortable time working window before extended cross-linking occurs. Once fully crosslinked, the resulting mold is easily demolded from the master thanks to its elasticity (Figure 2). The mold perfectly replicates the initial master features (relative shrinkage between master and mold can be neglected). Many molds can be fabricated from a single master. However, with extensive use, defects will start to appear on the master owing to the local adhesion of PDMS during mold release. For this reason, the surface of the master (for instance often made of silicon) is functionalized (e.g. with fluoroalkylsilanes) to decrease the surface energy, reducing the interactions with the PDMS chains.

When patterns with features smaller than $100 \mathrm{~nm}$ are needed, the excessive softness of PDMS can induce deformations of the mold shape while printing. This phenomenon has been widely studied both theoretically and experimentally ${ }^{22,23}$. As first demonstrated by Delamarche et al., ${ }^{22}$ only a fraction of the structures accessible by nanofabrication in hard materials will give stable structures in PDMS stamps. If the aspect ratio of the motifs is too high, structures can collapse under their own weight. During the stamping process, capillary forces can be strong enough to deform the stamp features and contact two neighboring structures. This is the case for densely packed structures, long grating lines or tightly spaced pillars. These structures are prone to pairing due to their high surface-to-volume ratio. Once collapsed it is hard to restore the PDMS features. Different ways of restoring the structures have been explored such as washing with low surface tension solvents or with water containing surfactants but with little success ${ }^{22}$. The easiest way to prevent the deformation of small patterns is to increase the rigidity of the PDMS material. 

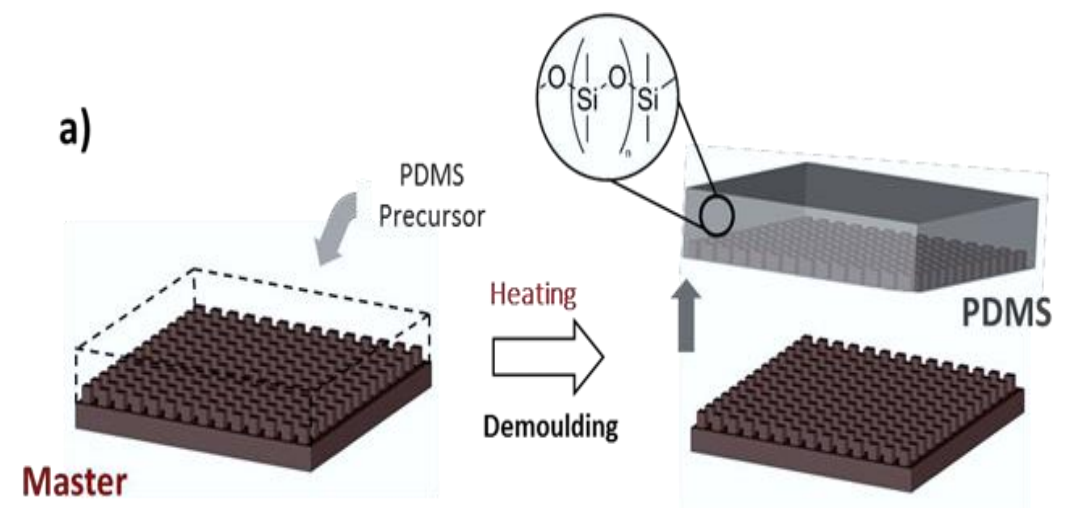

b)
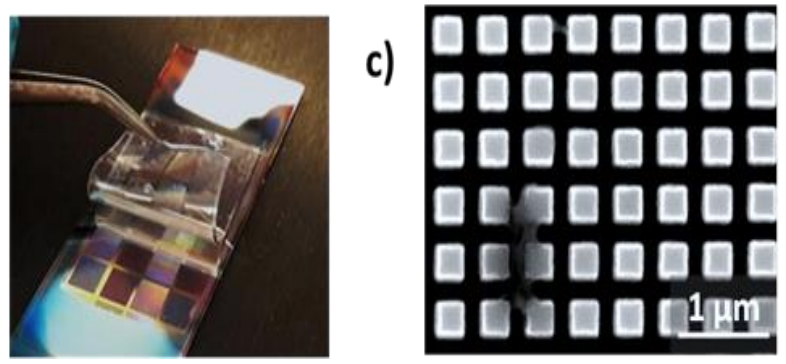

Figure 2. a) Schematic representation of the mold preparation. The precursor is poured onto the hydrophobized surface of the master and cured before demolding. b) Picture of a silicon master and its negative replica into a flexible mold. c) SEM image showing a defect on a silicon master after the preparation of many PDMS stamps.

Such PDMS, called hard-PDMS (h-PDMS), has been firstly developed by Schmid et al in $2000^{24}$. HardPDMS uses branched siloxanes, shorter cross-linkers, and a higher concentration of reactive groups compared to standard PDMS in order to increase the cross-linking density and the rigidity between the crosslinking points. The different concentrations in reactants and their ratios have been extensively studied ${ }^{21}$ and commercial products are now available. PDMS hardness is estimated through its Young's modulus that is about 20-30 MPa for conventional PDMS whereas it goes to 60 to $70 \mathrm{MPa}$ for h-PDMS. Other materials than PDMS can be used, such as siloxane-composites ${ }^{25}$ or thermo-plastic polymers ${ }^{26}$. However, they miss the intrinsic advantages of PDMS. Similarly, using pure h-PDMS has its limitations: a high-modulus polymer can increase the stress during the curing step, rendering it difficult to separate it from the master; h-PDMS has low flexibility, making conformal contact on rough surfaces rather difficult. The increased rigidity leads also to a poor accommodation to inhomogeneous stress during imprinting that might lead to plastic deformation or cracking of the stamp or of the substrate. In order to increase the rigidity and, at the same time, keep the advantages of low-modulus PDMS, hybrid stamps have been developed with a thin hPDMS layer of few microns that contains the patterns and a thick layer of standard PDMS of about $0.5 \mathrm{~mm}$ (Figure 2). In addition, to minimize in-plane deformation, for easier handling and automatization, this assembly (standard PDMS + hard PDMS) can then be backed by a thin glass plate.

Applying soft-NIL processes to directly imprint sol-gel metal oxides is highly interesting. However, it is quasi-unachievable due to two limitations: the impossibility to deform a brittle ceramic film and the difficulty to reach a plastic state at moderate temperature. A promising soft-NIL method on metal oxides exploits as-deposited sol-gel layers (xerogels). Xerogels are poorly cross-linked networks of sol-gel, organometallic precursors or hydrolyzed intermediates. Such gels remain flexible and will stiffen from 
advancing polycondensation during drying and aging of the films and finally with thermal annealing to form the metal oxides. The properties of xerogels can be exploited in soft-NIL at two conditions: (i) that imprinting takes place when the layer is in a gel-like phase and (ii) the demolding is made after sufficient solidification. Both these controls are challenging in sol-gel since the as-deposited layers undergo more or less fast cross-linking upon drying and mild thermal activation. These phenomena are generally accompanied by the release of water or solvent molecules that are trapped within the materials underneath the mold, affecting the replica morphology, density, and shrinkage factor. Eventually, the demolded material is converted into a purely inorganic and rigid metal oxide after calcination.

Sol-gel approaches rely on the use of polymeric or organic stabilizing agents in order to adjust the rheology and the precursor reactivity and achieve a good resolution and a large geometrical aspect ratio of the final 3D structures. The main drawback associated with this approach is the severe shrinkage following the evaporation of organic moieties during the annealing step (up to $60-80 \%$ vol ${ }^{27-30}$. Sol-gel formulations containing metal oxide nanoparticles (NPs) can be directly imprinted resulting in a reduced shrinkage ${ }^{30}$ and materials having lower density (resulting from the presence of pores associated with the NP packing). A compromise thus needs to be found between lower shrinkage and denser material. Of course, stabilizingagent-free xerogels can be used allowing for a reduced shrinkage factor. However, the very high viscosity of the intermediate xerogel will prevent efficient mass transfer within the sharp features of the mold. In fine, no increase in the aspect ratio will be found.

In order to promote the filling of the mold features, a technique called Degassed Assisted Patterning, taking advantage of the properties of PDMS to enhance its permittivity towards solvents has been developed. Historically, Degassed Assisted Patterning was used in microfluidics as a pump-free manipulation. First reported by Hosokawa et al in $2004^{31}$, it allowed to pre-store the pumping energy in the degassed PDMS in order to obtain a liquid flow in the PDMS channels during the experiment without the use of external pumping. Indeed, the solubility of a gas in PDMS follows Henry's law: the concentration of gas dissolved is proportional to the partial pressure of the gas around the mold.

(i)

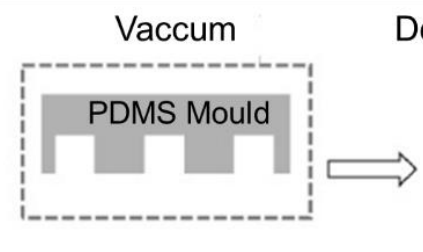

(ii)

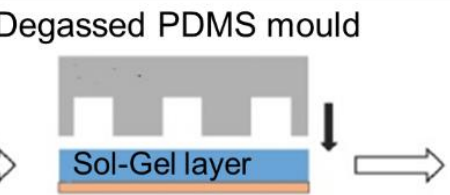

(iii)

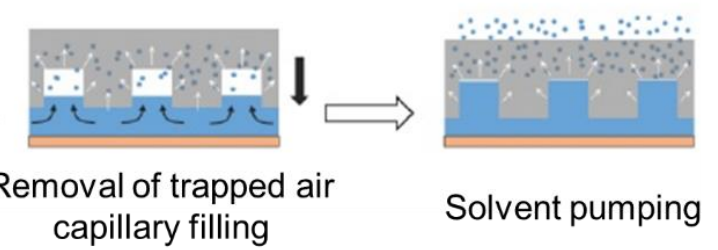

(vi)

Figure 3. Scheme presenting the Degassed Assisted patterning (DAP) process applied to the nanoimpression of sol-gel layers.

When a PDMS is degassed and brought back to the atmosphere, it equilibrates by absorbing air ${ }^{32}$. Therefore, by using degassed PDMS molds, a better filling of the cavities can be achieved. The patterning process can thus be broken down in four steps (Figure 3): i) the mold is first pumped under vacuum (P<10 mbars) for a few minutes; ii) straight after breaking the vacuum, the mold is deposited on as-prepared xerogels; iii) Air trapped in the mold cavities is easily pumped through the mold, promoting the filling of the cavities; iv) Solvents, generally trapped within the material underneath the mold, are pumped out improving the filling of the PDMS pattern cavities. To complete the imprinting step, consolidation of the 
xerogel is achieved through UV or thermal curing before un-molding and final thermal treatment is often required to achieve the pure metal oxide material.

The following Table 1 provides the characteristics of all replicas reviewed in this article for direct comparison. It gathers examples of patterns obtained with the different techniques discussed below (i.e. UV, thermal-, pressure-, or vapor-pressure-assisted NIL), with different inorganic materials, from different "resins" composed of sol-gel precursors, nanoparticles, organic binders and fluidizer, solvents, etc., and post-treated in various conditions. Dimensions and aspect ratios are provided as a benchmark for readers, knowing that they have been designed for related specific applications, taking into account the (controlled) anisotropic shrinkages occurring during drying under the mold and during post-curing after demolding. Shrinkage can therefore be detrimental since it creates internal tensile stresses fragilizing the mechanical stability of the pattern, but also beneficial since it can be predicted and used as a tool to control a feature's heigh in certain cases. Other important characteristics, such as controlled or residual porosity, stability for further processing or in operating conditions, adhesion to the substrate, etc. are also critical to meet the targeted requirements for applications. For instance, highly (meso)porous, high specific surface area materials are required for masse and/or charge transfer (sensors, electrodes), while dense materials are preferred for better control of optical parameters in optics and photonics. In some cases, such as for photoelectrodes, controlled porosity together with controlled refractive index and absorbance dispersions are necessary, which makes the fabrication by NIL extremely delicate. 
Table 1. Characterization of all replica reviewed in this article.

\begin{tabular}{|c|c|c|c|c|c|c|}
\hline Technique & Materials & $\begin{array}{c}\text { Final thermal } \\
\text { annealing }\end{array}$ & $\begin{array}{c}\text { Dimensions } \\
(\mathrm{nm})\end{array}$ & $\begin{array}{c}\text { Aspect } \\
\text { ratio } \mathrm{H} / \mathrm{W}\end{array}$ & Applications & Reference \\
\hline UV NIL & $\mathrm{TiO}_{2}-\mathrm{SiO}_{2}$-PMMA & $150{ }^{\circ} \mathrm{C}$ & $127 * 105$ & 1.2 & - & {$[35]$} \\
\hline UV NIL & $\mathrm{TiO}_{2}$ & None & $\begin{array}{l}230 * 265 \\
200 * 35\end{array}$ & $\begin{array}{c}0.8 \\
6 \\
\end{array}$ & - & [30] \\
\hline UV NIL & Ti/TMSPM & $120^{\circ} \mathrm{C}$ & $80 * 2000$ & & - & [36] \\
\hline UV NIL & ZnO/Benzyl methacrylate (BzMA) & None & $300 * 300$ & 1 & LEDs & [37] \\
\hline UV NIL & $\mathrm{ZnO}$ & $350^{\circ} \mathrm{C}$ & $400 * 200$ & 2 & - & [38] \\
\hline S-FIL & $\mathrm{TiO}_{2}$ & $450^{\circ} \mathrm{C}$ & $53 * 62$ & 1 & & [39] \\
\hline UV NIL & $\mathrm{TiO}_{2}$ & None & $400 * 300$ & - & Photonic crystal & [41] \\
\hline UV NIL & $\mathrm{SiO}_{2}$ & $500^{\circ} \mathrm{C}$ & $1.5^{*} 1.5 \mu \mathrm{m}$ & 1 & - & [42] \\
\hline UV NIL & $\mathrm{ZnO}$ & None & $\begin{array}{c}\text { Random } \\
\text { pyramids, } \\
(\sim 1 \mu \mathrm{m})\end{array}$ & - & Solar cells & [45] \\
\hline UV NIL & $\mathrm{ZnO}$ & None & $\begin{array}{c}\text { Random } \\
\text { pyramids, } \\
(\sim 1 \mu \mathrm{m})\end{array}$ & - & Solar cells & [43] \\
\hline Pressure T-NIL & PEDOT: PSS & None & $300 * 70$ & - & Solar cells & [46] \\
\hline Pressure T-NIL & AuNPs & $140^{0} \mathrm{C}$ & $405 * 750$ & - & - & [47] \\
\hline Pressure T-NIL & $\mathrm{TiO}_{2}$ & None & $\begin{array}{c}260 * 200 \\
240 * 200 \\
1.35 * 2.6 \mu \mathrm{m}\end{array}$ & $\begin{array}{l}1.3 \\
1.2 \\
0.5\end{array}$ & - & {$[48]$} \\
\hline Pressure T-NIL & $\begin{array}{c}\mathrm{Al}_{2} \mathrm{O}_{3}, \mathrm{Ga}_{2} \mathrm{O}_{3}, \mathrm{In}_{2} \mathrm{O}_{3}, \mathrm{Y}_{2} \mathrm{O}_{3}, \mathrm{~B}_{2} \mathrm{O}_{3} \\
\mathrm{TiO}_{2}, \mathrm{SnO}_{2}, \mathrm{ZrO}_{2}, \mathrm{GeO}_{2}, \mathrm{HfO}_{2} \\
\mathrm{Nb}_{2} \mathrm{O}_{5}, \mathrm{Ta}_{2} \mathrm{O}_{5}, \mathrm{~V}_{2} \mathrm{O}_{5}, \text { and } \mathrm{WO}_{2}\end{array}$ & $300-475^{\circ} \mathrm{C}$ & - & 1 & - & {$[40]$} \\
\hline Pressure T-NIL & $\mathrm{ZnO}$ & $250{ }^{\circ} \mathrm{C}$ & $200 * 800$ & 0.5 & - & [49] \\
\hline Pressure T-NIL & $\mathrm{SiO}_{2}$ & $550{ }^{\circ} \mathrm{C}$ & - & 4 & - & [29] \\
\hline Pressure T-NIL & $\mathrm{SiO}_{2}$ & None & $150 * 50$ & 1.2 & - & {$[50]$} \\
\hline Pressure T-NIL & $\mathrm{TiO}_{2}$ & $500^{\circ} \mathrm{C}$ & $270 * 900$ & - & Solar cells & [51] \\
\hline Thermal NIL & Lead Zirconate titanate & $650^{\circ} \mathrm{C}$ & $25 * 380$ & 0.07 & - & {$[52]$} \\
\hline Thermal NIL & $\mathrm{TiO}_{2}$ and ITO & $500^{\circ} \mathrm{C}$ & $340 * 340$ & - & - & [32] \\
\hline $\begin{array}{c}\text { Environmental } \\
\text { Thermal NIL }\end{array}$ & $\mathrm{TiO}_{2} / \mathrm{MOF}(\mathrm{ZIF} 8)$ & $450^{\circ} \mathrm{C}$ & $240 * 200$ & 1.2 & Sensors & [53] \\
\hline $\begin{array}{l}\text { Environmental } \\
\text { Thermal NIL }\end{array}$ & $\mathrm{TiO}_{2}$ & $450^{\circ} \mathrm{C}$ & - & 1 & - & {$[54]$} \\
\hline $\begin{array}{l}\text { Environmental } \\
\text { Thermal NIL }\end{array}$ & $\mathrm{TiO}_{2}$ & $450{ }^{\circ} \mathrm{C}$ & - & $\begin{array}{c}0.5 \\
0.92 \\
1\end{array}$ & - & [55] \\
\hline $\begin{array}{c}\text { Environmental } \\
\text { Thermal NIL }\end{array}$ & $\mathrm{TiO}_{2} / \mathrm{Ag}$ & $450^{\circ} \mathrm{C}$ & - & 1 & Solar cells & {$[56]$} \\
\hline $\begin{array}{c}\text { Environmental } \\
\text { Thermal NIL }\end{array}$ & $\begin{array}{c}\mathrm{TiO}_{2}, \mathrm{Al}_{2} \mathrm{O}_{3}, \mathrm{Y}-\mathrm{ZrO}_{2}, \mathrm{Methyl} \mathrm{SiO}_{2}, \\
\text { mesoporous } \mathrm{SiO}_{2}\end{array}$ & $450{ }^{\circ} \mathrm{C}$ & - & 1 & - & [57] \\
\hline $\begin{array}{c}\text { Environmental } \\
\text { Thermal NIL }\end{array}$ & $\begin{array}{r}\mathrm{TiO}_{2} \\
\mathrm{SiO}_{2} \\
\end{array}$ & $400{ }^{0} \mathrm{C}$ & $\begin{array}{c}25 * 700 \\
100 * 1000 \\
\end{array}$ & - & - & {$[58]$} \\
\hline $\begin{array}{c}\text { Environmental } \\
\text { Thermal NIL }\end{array}$ & $\mathrm{TiO}_{2}$ & $450^{0} \mathrm{C}$ & - & 1 & - & [59] \\
\hline $\begin{array}{c}\text { Environmental } \\
\text { Thermal NIL }\end{array}$ & Methylated silica $\left(\mathrm{Si}_{4} \mathrm{O}_{7} \mathrm{Me}_{2}\right)$ & $450{ }^{\circ} \mathrm{C}$ & $200 * 120$ & 1.7 & ARC & [60] \\
\hline Direct printing & $\mathrm{SiO}_{2}$ & $200^{0} \mathrm{C}$ & 400 & - & Solar cells & [61] \\
\hline Direct printing & $\mathrm{BaTiO}_{3}$ & None & $400 * 120$ & 3 & Pietzoelectric & {$[62]$} \\
\hline Direct printing & $\mathrm{SiO}_{2}$ & $200^{\circ} \mathrm{C}$ & $120 * 245$ & - & Solar cells & [64] \\
\hline Thermal NIL & $\mathrm{LiMn}_{2} \mathrm{O}_{4}(\mathrm{LMO})$ & $400{ }^{\circ} \mathrm{C}$ & $\begin{array}{c}420 * 390 \\
1.1 \mathrm{um} * 1.9 \mathrm{um} \\
800 \mathrm{~nm} * 3.1 \mathrm{um} \\
\end{array}$ & $\begin{array}{l}0.9 \\
1.7 \\
3.8\end{array}$ & $\begin{array}{l}\text { Electrodes for } \\
\text { batteries }\end{array}$ & [56] \\
\hline Thermal NIL & $\mathrm{TiO}_{2}$ nanoparticle & $750^{\circ} \mathrm{C}$ & $200 * 200$ & 1 & $\begin{array}{c}\text { Electrodes for } \\
\text { batteries }\end{array}$ & [55] \\
\hline
\end{tabular}




\section{UV-NIL processes}

UV-NIL method is one of the most developed and used in recent years. From its outset till today, it has been adapted to a plethora of different materials, including organic, hybrid organic/inorganic, and inorganic metals and metal oxide materials from sol-gel solutions and/or nanoparticles (NPs) dispersions. A prerequisite is that the imprinted materials (precursors) need to absorb UV radiation. UV-NIL processes involve several steps, starting first with liquid deposition (e.g. spin, dip, ink, spray, etc.) of the "resin" solution, followed by imprinting with a UV resistant and transparent mold stamp, composed of typically Polydimethylsiloxane (PDMS), poly-urethane-acrylate (PAU), Quartz, or Perfluoropolyether (PFPE), so that curing through UV exposure takes place directly underneath the mold. Once the material is cross-linked enough, the mold is delicately peeled off to prevent damaging the replica. UV-NIL enables working at room temperature with low or no external pressure. It thus does not require temperature cycling and leads to relevantly high throughput on substrates compatible with UV curing. UV-NIL has been demonstrated to be a high-volume and cost-effective patterning technique, able to achieve sub-10 $\mathrm{nm}$ resolution.

\subsection{UV-NIL from hybrid (organic/inorganic) resins}

Kim et al. in $2005^{33}$, reported the fabrication of photonic crystal $\mathrm{TiO}_{2}-\mathrm{SiO}_{2}-\mathrm{PMMA}$ hybrid structures by UV-NIL. The sol-gel derived solution was prepared from 3-(Trimethoxysilyl) propyl methacrylate (MPTMS), diphenylsilanediol (DPSD) and titanium ethoxide $\left(\mathrm{Ti}_{(}\left(\mathrm{OC}_{2} \mathrm{H}_{5}\right)_{4}\right)$ precursors, together with a photoinitiator (i.e. Irgacure 184). The nanoimprint was performed after deposition of the solution using a PDMS mold with ring patterns and applying UV $\left(365 \mathrm{~nm} / 2.5 \mathrm{~J}_{\mathrm{cm}} \mathrm{cm}^{-2}\right)$ irradiation for $30 \mathrm{~s}$. After unmolding, the sample was cured at $150{ }^{\circ} \mathrm{C}$ for $3 \mathrm{~h}$. They reported a relatively low shrinkage of 2-2.5 vol\% of the hybrid organic-inorganic replicate yielding the following final dimensions: diameter $105 \mathrm{~nm}$ and $127 \mathrm{~nm}$ depth (aspect ratio $=1.2$ ). In 2009, Park et al. ${ }^{28}$ developed a formulation based on photosensitive titanium (titanium-n-butoxide bis (2-ethyl-hexanoate) single precursor. The solution was first deposited on silicon substrates by spin coating before being imprinted with different molds such as PDMS and PUA (PolyUrethane Acrylate) under 2-bar pressure and $365 \mathrm{~nm}$ radiation for $20 \mathrm{~min}$. No photo-initiator was used since the cross-section of Ti centers was sufficient to trigger the cross liking of the network. They reported faithful replication for different features, such as $180 \mathrm{~nm}$ in depth and $265 \mathrm{~nm}$ in diameter dots from a PDMS mold, or lines of $200 \mathrm{~nm}$ height and $35 \mathrm{~nm}$ wide from a PUA mold, reaching excellent aspect ratio of $\sim 6$ (see Figure 4). In 2010, P. Prosposito et al. ${ }^{34}$ used a formulation based on MPTMS, Titanium propoxide, acetylacetone chelating agent, and Irgacure 184 (CIBA) photoinitiator. The initial film was spin-coated on $\mathrm{Si}$ wafers and pre-baked at $80^{\circ} \mathrm{C}$ for $30 \mathrm{~min}$ for removal of residual solvent. The structures were imprinted by pressing the PDMS stamp on the layer under $300 \mathrm{~W}$ filtered $(<400 \mathrm{~nm}) \mathrm{Xe}-\mathrm{Hg}$ lamp for $1 \mathrm{~min}$. After unmolding, curing at $120{ }^{\circ} \mathrm{C}$ for $90 \mathrm{~min}$ was applied. The final structures of the grating were $80 \mathrm{~nm}$ in height and $2 \mu \mathrm{m}$ wide. In this process, an $80 \mathrm{~nm}$ residual layer was retained and $\sim 6 \%$ of shrinkage was measured after the final densification. In these three works, the final replicas remain titanium-organic-based materials, since no high-temperature annealing was applied. Removal of the organic linkers by high thermal treatment would have led to dense $\mathrm{TiO}_{2}$ accompanied by a more pronounced shrinkage. 


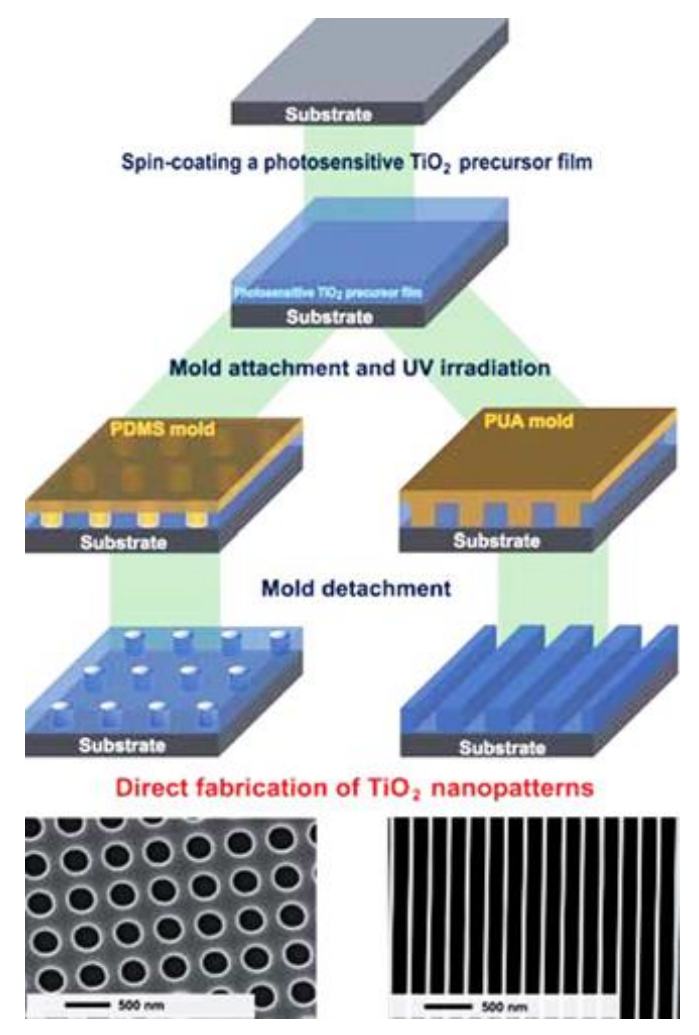

Figure 4. Schematic diagram of ultraviolet-assisted nanoimprint lithography process using the photosensitive titanium organic compound titanium (IV) di-n-butoxide bis(2 ethylhexanoate $)^{28}$. Reprinted with permission from [Park, H.-H.; Choi, D.-G.; Zhang, X.; Jeon, S.; Park, S.-J.; Lee, S.-W.; Kim, S.; Kim, K.; Choi, J.-H.; Lee, J.; Yun, D. K.; Lee, K. J.; Park, H.-H.; Hill, R. H.; Jeong, J.-H. Photo-Induced Hybrid Nanopatterning of Titanium Dioxide via Direct Imprint Lithography. J. Mater. Chem. 2010, 20 (10), 1921. https://doi.org/10.1039/b921343k.] Copyright 2010, ROYAL SOCIETY OF CHEMISTRY.

Jo et al. ${ }^{35}$ elaborated $\mathrm{ZnO}$ polymer composite structures from nanoparticles. Firstly, they prepared a $\mathrm{ZnO}$ Nanoparticles (NPs) dispersion in the required resin system (ethanol and benzyl methacrylate (BzMA)), which was spin-coated (3000 rpm for $30 \mathrm{~s}$ ) on a Si substrate. The replication process included placing the PDMS mold onto the thin-film, for 10 min under 5 atm pressure with $365 \mathrm{~nm}$ UV light (Figure 5 (c)). Then, regular patterns, such as line grating (width $200 \mathrm{~nm}$ and height $250 \mathrm{~nm}$ ) and cylindrical pillars $(300 \mathrm{~nm}$ diameter and height) were formed (Figure 5 (a) and (b)). In this example, the organic resin plays the role of UV-binder allowing for a large proportion of the material to be composed of $\mathrm{ZnO}$. 

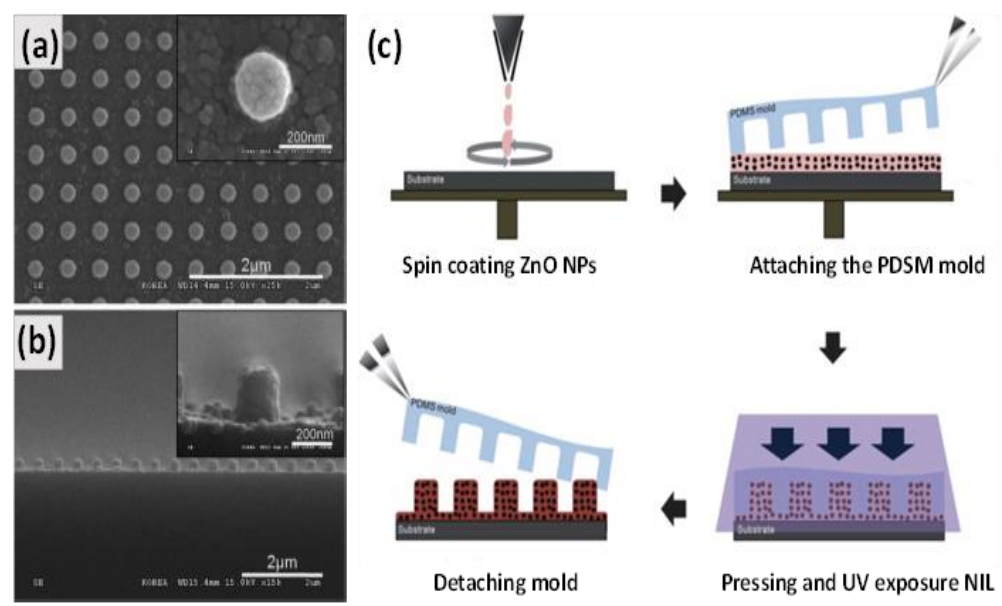

Figure 5. SEM micrographs of $\mathrm{ZnO}$ nano-particles containing a submicron-scale pillar structure: (a) top view and (b) cross-section view. (c) Schematic diagram of the fabrication process of $\mathrm{ZnO}$ nano-particles containing functional patterns by UV imprint lithography ${ }^{35}$. Reprinted with permission from [Jo, H.-B.; Byeon, K.-J.; Lee, H.; Kwon, M.-H.; Choi, K.-W. Fabrication of ZnO Nano-Structures Using UV Nanoimprint Lithography of a $\mathrm{ZnO}$ Nano-Particle Dispersion Resin. J. Mater. Chem. 2012, 22 (38), 20742. https://doi.org/10.1039/c2jm32509h] Copyrigth 2012, ROYAL SOCIETY OF CHEMISTRY.

In 2014, Chong et al ${ }^{36}$ used $\mathrm{ZnO}$ precursor-resin formulation obtained by dissolving Zinc acetate dihydrate $\left(\mathrm{Zn}\left(\mathrm{CH}_{3} \mathrm{COO}\right)_{2} .2 \mathrm{H}_{2} \mathrm{O}\right)$, 2-nitrobenzaldehyde (UV-linker), with mono-ethanolamine (MEA, $\left(\mathrm{NH}_{2} \mathrm{CH}_{2} \mathrm{CH}_{2} \mathrm{OH}\right)$ in 2-methoxyethanol $\left(\mathrm{CH}_{3} \mathrm{OCH}_{2} \mathrm{CH}_{2} \mathrm{OH}\right)$. The sol-gel-based $\mathrm{ZnO}$-precursor resin was spin-coated (3500 rpm, 1min) on $\mathrm{SiO}_{2} / \mathrm{Si}$ and on flexible polyimide substrates before a PUA mold was applied on it. The material was crosslinked under $365 \mathrm{~nm}$ exposure for $3 \mathrm{~min}$ under air pressure of $0.02 \mathrm{MPa}$ air pressure. The grating line patterns were $200 \mathrm{~nm}$ in height, aspect ratio of about $\sim 2$, and $1 \mu \mathrm{m}$ periodicity after the final annealing at $350^{\circ} \mathrm{C}$ for $60 \mathrm{~min}$. Although they did not report any shrinkage, they observed a residual layer of $30 \mathrm{~nm}$ that was completely removed by wet etching in $0.025 \% \mathrm{HNO}_{3}$. Additional growth of $\mathrm{ZnO}$ was applied by keeping the $\mathrm{ZnO}$ nanostructures in an aqueous solution of Zinc nitrate $\left(\mathrm{Zn}\left(\mathrm{NO}_{3}\right)_{2}\right.$. $\left.6 \mathrm{H}_{2} \mathrm{O}\right)$ in the presence of hexamethylenetetramine $\left(\mathrm{C}_{6} \mathrm{H}_{12} \mathrm{~N}_{4}\right)$ and polyethylenimine (PEI)).

Step-and-Flash Imprint Lithography (S-FIL) was used by Ganesan et al. and Dinachali et al. to prepare organic polymer patterns ${ }^{37,38}$. Contrary to common UV-NIL, S-FIL relies on photopolymerization chemistry of low viscosity resins, enabling to fill the mold cavities by the capillary forces with low mechanical pressure at room temperature. This S-FIL UV-NIL method was exploited by Ganesam et al. in $2012^{37}$ to elaborate $\mathrm{TiO}_{2}$ nanostructures. They first prepared $\mathrm{TiO}_{2}$ resists by directly mixing methacrylic acid, ethylene glycol diacrylate, isobutyl acrylate (monomer flow), and photo-initiator with Titanium (IV) ethoxide. This solution was spin-coated on Si wafer before applying the PDMS mold and irradiating with UV $\left(300 \mathrm{~mW} \mathrm{~cm}^{-2}\right)$ for $60 \mathrm{~s}$. After unmolding, the imprinted patterns were heat-treated at $450{ }^{\circ} \mathrm{C}$ for $1 \mathrm{~h}$ in air to remove the organics and convert the inorganic parts into Anatase as $100 \mathrm{~nm}$ dimples, $200 \mathrm{~nm}$ squares and $100 \mathrm{~nm}$ line gratings. The latter underwent a shrinkage to approximately one-quarter in transversal and longitudinal directions, maintaining the original aspect ratio around 1 . The same group transposed the S-FIL technique to various other metal oxide ${ }^{38}$ using formulations composed of $\mathrm{Al}, \mathrm{Hf}, \mathrm{Ti}, \mathrm{Zr}, \mathrm{Nb}$ and $\mathrm{Ta}$ alkoxides combined with a polymerizable chelating agents 2-(methacryloyloxy)ethyl acetoacetate (MAEAA), a reactive diluent, a crosslinker, and a photo-initiator. After spin-coating on Si substrates, the quartz template was applied and the cross-linking was obtained after $60 \mathrm{~s}$ under UV light $\left(4.4 \mathrm{mWcm}^{-2}\right) .20-25 \mathrm{~nm}$ wires with an aspect ratio of about 1 were obtained after annealing at $475^{\circ} \mathrm{C}$ for $1 \mathrm{~h}$. The decomposition-induced, high shrinkage was 
determined to be around $80 \%$ in each case (see Table 2), which is due to the high proportion of organic stabilizer and fluidizer required in this process.

Table 2. Summary of the Approximate Feature Size Reduction at Every Step of the Imprinting Process of Various Oxides with a $100 \mathrm{~nm}$ Line and Space Grating Mold (Aspect Ratio 1) ${ }^{38}$. (Reprinted with permission [Dinachali, S. S.; Saifullah, M. S. M.; Ganesan, R.; Thian, E. S.; He, C. A Universal Scheme for Patterning of Oxides via Thermal Nanoimprint Lithography. Adv. Funct. Mater. 2013, 23 (17), 2201-2211. https://doi.org/10.1002/adfm.201202577] Copyright 2013, JOHN WILEY AND SONS ADVANCED FUNCTIONAL MATERIAL.

\begin{tabular}{|c|c|c|c|c|c|}
\hline \multirow{2}{*}{ resin } & \multicolumn{2}{|c|}{ The feature size of the imprint after S-FIL } & \multicolumn{2}{|c|}{$\begin{array}{l}\text { Oxide feature size after the heat treatment of imprinted } \\
\text { structures }\end{array}$} & \multirow{2}{*}{$\begin{array}{l}\text { Total feature size } \\
\text { reduction concerning } \\
\text { mold feature size }(\%\end{array}$} \\
\hline & $\begin{array}{l}\text { Width of imprint } \\
(\mathbf{n m})\end{array}$ & $\begin{array}{l}\text { Feature size reduction } \\
(\%)\end{array}$ & $\begin{array}{l}\text { Width of the oxide feature } \\
(\mathbf{n m})\end{array}$ & $\begin{array}{l}\text { The feature size of reduction } \\
(\%)\end{array}$ & \\
\hline $\mathbf{A l}_{2} \mathbf{O}_{3}$ & 85 & $15 \%$ & 20 & $76 \%$ & $\mathbf{8 0} \%$ \\
\hline $\mathrm{HfO}_{2}$ & 86 & $14 \%$ & 20 & $77 \%$ & $\mathbf{8 0 \%}$ \\
\hline $\mathrm{TiO}_{2}$ & 83 & $17 \%$ & 18 & $78 \%$ & $82 \%$ \\
\hline $\mathrm{ZrO}_{2}$ & 79 & $21 \%$ & 22 & $72 \%$ & $78 \%$ \\
\hline $\mathrm{Nb}_{2} \mathrm{O}_{5}$ & 76 & $24 \%$ & 25 & $68 \%$ & $75 \%$ \\
\hline $\mathrm{Ta}_{2} \mathrm{O}_{5}$ & 72 & $21 \%$ & 25 & $65 \%$ & $75 \%$ \\
\hline
\end{tabular}

One advantage of NIL methods is the possibility to elaborate 3D patterns by replication layer atop layer. In 2014, Beaulieu et al. ${ }^{39}$ reported $\mathrm{TiO}_{2} 3 \mathrm{D}$ photonic crystal structures (PCs) from line gratings pilling. They started from a dispersion of $\mathrm{TiO}_{2}$ NPs that was first transferred into a mixture of $\mathrm{N}$-methylpyrrolidone (NMP) and methanol $(\mathrm{MeOH})$ before mixing with UV-curable polymer resist (Norland Optical Adhesive 60). After spin coating, the formulation, capillary infiltration into the PDMS cavities was facilitated by the

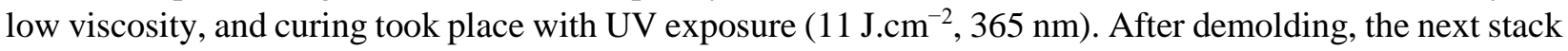
was applied with the same replication procedures, and patterns with $300 \mathrm{~nm}$ depth (D) and $400 \mathrm{~nm}$ line width (LW) were obtained. Even with 2 successive imprints, the obtained aspect ratio remained as low as before in one stack ( $\mathrm{LW}=400 \mathrm{~nm}, \mathrm{D}=300 \mathrm{~nm}$ ), confirming the shrinkage induced by the departure of the sacrificial organic binders. A similar approach was used by Yoon et al. in 2020 to elaborate high aspect ratio $\mathrm{TiO}_{2}$ patterns meta-lenses ${ }^{40} . \mathrm{TiO}_{2}$ nanoparticles composite were prepared by mixing Dipentaerythritol penta/hexa-acrylate binder, 1-Hydroxycyclohexyl phenyl ketone as photoinitiator, and $\mathrm{TiO}_{2} \mathrm{NPs}$ dispersed in methyl isobutyl ketone. $3 \mu \mathrm{L}$ of the solution was dropped on a glass substrate and imprinted with PDMS molds under UV light and 2 bar pressure for 5 min. After demolding, the obtained line and pillar features showed lateral dimensions between 100 and $400 \mathrm{~nm}$ for a constant height of around $700 \mathrm{~nm}$. Varying the $\mathrm{TiO}_{2}$ content between $0 \%$ and $100 \%$ allowed to adjust the refractive index of the material between 1.5 and 2 in the visible. Alternatively, Arisoy et al. ${ }^{41}$ reported the elaboration of anti-microbial pillar arrays (called sharkskin patterns) from mixtures of $\mathrm{TiO}_{2}$ nanoparticles inorganic source and NOA (Norland Optical Adhesive 60) or TEOS as binders, with several compositions. After spin-coating on poly-ethylene terephthalate (PET) substrates, the imprinting took place with PDMS stamps under $50^{\circ} \mathrm{C}$ for $30 \mathrm{~min}$, followed by a UV-curing $\left(365 \mathrm{~nm}, 11 \mathrm{~J} / \mathrm{cm}^{2}\right.$ ) or a NIR-curing (Adphos, $3 \mathrm{~kW}$ ), for NOA-containing or silica-containing systems, respectively. The final shark-skin patterns were composed of $1.6 \mu \mathrm{m}$ height and $1.3 \mu \mathrm{m}$ width pillars in every case, suggesting that both types of binders (organic or inorganic) were efficient in the process. 

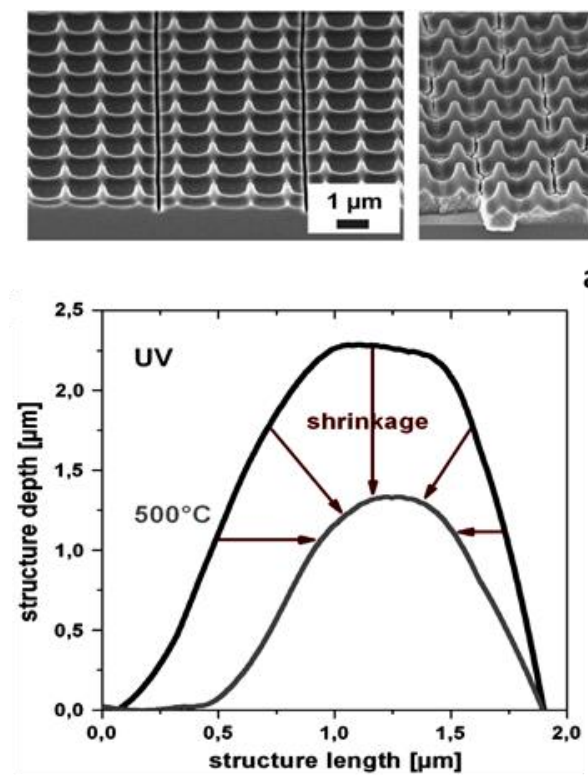

b)

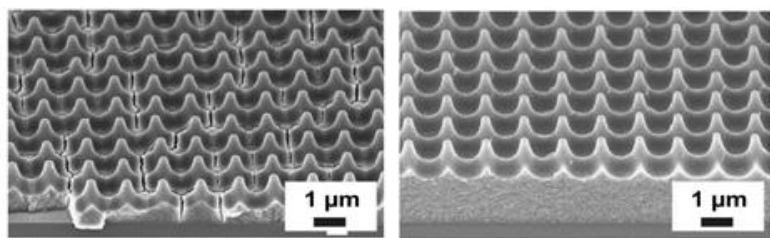

a)

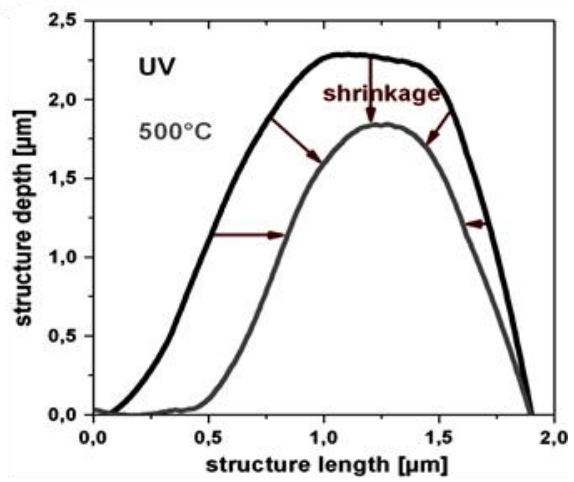

c)

Figure 6. (a) SEM images of nanostructured films after thermal treatment, respective solutions were prepared with pure binder system, a sol-gel matrix with $40 \mathrm{wt} \%$ spherical $\mathrm{SiO}_{2}$ particles content and a solgel matrix with $40 \mathrm{wt} \%$ branched $\mathrm{SiO}_{2}$. AFM profiles of nanostructures were obtained with a pure binder (b) and a sol-gel matrix with $40 \mathrm{wt} \%$ branched $\mathrm{SiO}_{2}$ particles (c). ${ }^{42}$ Reprinted with permission from [Back, F.; Bockmeyer, M.; Rudigier-Voigt, E.; Löbmann, P. Periodic Nanostructures Imprinted on HighTemperature Stable Sol-Gel Films by Ultraviolet-Based Nanoimprint Lithography for Photovoltaic and Photonic Applications. Thin Solid Films 2014, 562, 274-281. https://doi.org/10.1016/j.tsf.2014.04.082] Copyright 2014, ELSEVIER- THIN SOLID FILMS).

In 2014, Back et al, ${ }^{42}$ reported the impact of silica-based formulation on the shrinkage and crack formation during densification on glass through UV-NIL. Two sol-gel sources of $\mathrm{SiO}_{2}$ were used: the binder composed of Tetraethoxysilane (TEOS) and 3-glycidoxypropyltriethoxysilane (GPTES) (hybrid polymeric binder) and colloids composed of $\mathrm{SiO}_{2} \mathrm{NPs}$. Three formulations $\left(\mathrm{SiO}_{2}\right.$ spherical, branched and pure binder) where studied by mixing the two sources in different proportions. Thin films were deposited by dip-coating (withdrawal rate $10 \mathrm{~cm} / \mathrm{min}$ ) and curing by UV irradiation for $60 \mathrm{sec}$ (Dry max 5000EC, 400 Watt) under the PDMS mold, followed by a thermal annealing at $500{ }^{\circ} \mathrm{C}$ for $1 \mathrm{~h}$. The final patterns were composed of 2 $\mu \mathrm{m}$ periodic features with lower degrees of shrinkage for higher contents in condensed $\mathrm{SiO}_{2}$ (see Figure 6 and Table 3). 
Table 3. Comparison of residual stress and film porosity of pure binder system and particle-filled systems with a particle content of $40 \mathrm{wt} \%$ after thermal curing at $500{ }^{\circ} \mathrm{C}$ for $1 \mathrm{~h} .{ }^{42}$ Reprinted with permission from[ Back, F.; Bockmeyer, M.; Rudigier-Voigt, E.; Löbmann, P. Periodic Nanostructures Imprinted on HighTemperature Stable Sol-Gel Films by Ultraviolet-Based Nanoimprint Lithography for Photovoltaic and Photonic Applications. Thin Solid Films 2014, 562, 274-281. https://doi.org/10.1016/j.tsf.2014.04.082] copyright 2014, ELSEVIER- THIN SOLID FILMS).

\begin{tabular}{|c|c|c|c|c|}
\hline Morphology & Structure accuracy [\%] & Shrinkage of volume [\%] & Axial shrinkage [\%] & Lateral shrinkage [\%] \\
\hline Pure binder & 71 & 64 & 53 & 11 \\
\hline $\mathbf{4 0 \%}$ spherical & 85 & 37 & 24 & 8 \\
\hline $\mathbf{4 0 \%}$ branched & 91 & 17 & 16 & 1 \\
\hline
\end{tabular}

When the annealing temperature increases from 200 to $500{ }^{\circ} \mathrm{C}$, features lose $64 \%$ in volume, which can be considerably reduced when using high concentrations of dense silica sources. In addition, less shrinkage is accompanied by less cracks, suggesting that the presence of NPs allowed for better stress relaxation during densification.

Whatever the imprinting method, one has to find conditions to enable a faithful infiltration of the mold cavities with a fluid enough resin and with minimal deformation. Organic fluidizers and binders are generally used to achieve these conditions and facilitate replication. A limited proportion of them is needed when used with nanoparticle inorganic sources, which leads to reduced related shrinkage for inorganic rich materials, as a result of their lower surface interacting with the medium. Potential issues of using nanoparticles lay in the need of a longer treatment for consolidation, the creation of residual inter-particle porosity, and the formation of a rough surface associated with the size of the particles.

\subsection{UV-NIL with pure inorganic materials}

A strategy to overcome the latter potential issues has been reported by several groups, especially with $\mathrm{ZnO}$ due to its interesting electrical and optical characteristics. In 2010 and 2011, the group of Escaree and Battagelia ${ }^{43,44,45}$ reported the elaboration of different structures with an original approach schemed in Figure 7. 

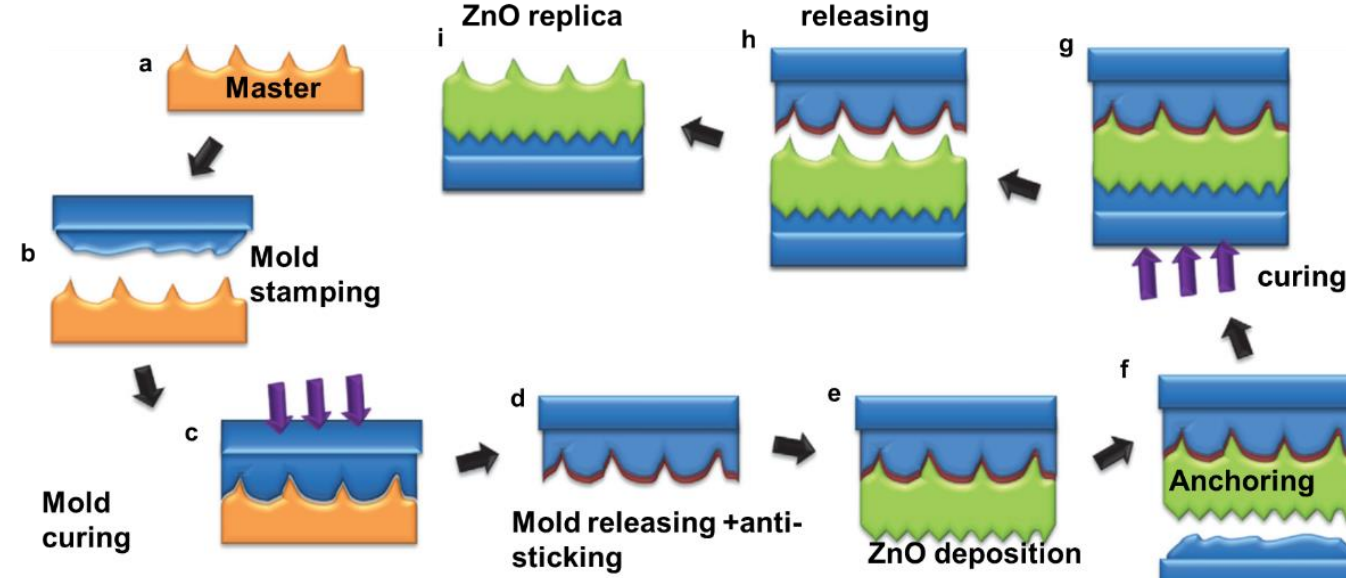
sticking

Figure 7. Schematic process flow for nanomoulding of $\mathrm{ZnO}$. a-i, The process can be divided into mold fabrication (b-d), ZnO deposition (e) and layer transfer (f-i) ${ }^{44}$. Reprinted with permission from [Battaglia, C.; Escarré, J.; Söderström, K.; Charrière, M.; Despeisse, M.; Haug, F.-J.; Ballif, C. Nanomoulding of Transparent Zinc Oxide Electrodes for Efficient Light Trapping in Solar Cells. Nat. Photonics 2011, 5 (9), 535-538. https://doi.org/10.1038/nphoton.2011.198] Copyright 2011, SPRINGER NATURE-NATURE PHOTONIC.

Firstly, flexible molds (PDMS ${ }^{45}$ and PEN ${ }^{45,43,44}$ ) were coated with a 10-nm-thick sputtered chromium layer and an anti-adhesion monolayer of trichloro (tridecafluorooctyl) silane. $\mathrm{ZnO}$ was then deposited on the mold by chemical vapor deposition (LP-CVD) at $180{ }^{\circ} \mathrm{C}$ and using $\left(\mathrm{C}_{2} \mathrm{H}_{5}\right)_{2} \mathrm{Zn}$ and $\mathrm{H}_{2} \mathrm{O}$ as precursor gases. Asprepared samples were anchored on a glass substrate under UV exposure $(365 \mathrm{~nm})$ with 1 bar pressure for $20 \mathrm{~min}$. The mold was thus released and the patterns of pyramids, gratings, dimple pillars with relatively large size $(\sim 1 \mu \mathrm{m})$ were obtained. The use of dense $\mathrm{ZnO}$ allowed producing patterns that did not require any additional consolidation-induced shrinkage. Still, this method remains relatively cumbersome compared to traditional UV NIL.

\section{Thermal NIL}

The thermal NIL (also known as hot embossing) process is the earliest type of NIL introduced by S.Y. $\mathrm{Chou}^{18}$. T-NIL is one of the most attractive NIL techniques due to its simplicity and capability to replicate nanostructures into various types of materials onto various thermally resistant substrates. Mold stamps can be PDMS, Nikel, Quartz, PFPE, PUA, etc. In typical T-NIL processes a stamp mold is brought in contact with the resin, the whole system is heated-up either to soften a thermoplastic resin (that will regain its rigidity after cooling) or to crosslink a thermally curable fluidic resin. T-NIL is categorized in three different methods: Pressure thermal NIL, Direct thermal NIL and Vapor Pressure Thermal NIL. They differ by the underlying phenomena used to fill-up the mold cavities. In Pressure T-NIL, a slight mechanical pressure helps the viscous resin to infiltrate the mold, while in Direct T-NIL the resin is fluid enough for infiltration that can be enhanced by heating or pumping through the mold. In Vapor-Pressure T-NIL, one adjusts the vapor pressure of the solvent (mainly water or ethanol) in the chamber to stabilize the resin content in the solvent at a given value defined by adsorption/desorption equilibrium, adjusting, then, the viscosity for infiltration. This latter method can be used in combination with pumping. 


\subsection{Pressure thermal NIL}

\subsubsection{Pressure T-NIL combined with dry deposition of the final material}

Transfer patterning of inorganic materials was reported by Kang et al in $2008^{46}$. They deposited by electron beam evaporation a $40 \mathrm{~nm}$ thick layer of metals $(\mathrm{Cu}, \mathrm{Au}$ and $\mathrm{Ag})$ on a patterned PDMS and pressed it $(<40$ $\mathrm{KPa}$ ) onto poly (3,4-ethylenedioxythiophene)/poly (styrene sulfonic acid) (PEDOT:PSS) at $80{ }^{\circ} \mathrm{C}$ to deposit electrode wires. Park et al. ${ }^{47}$ replicated different micro/nanoscale structures by dispersing $2-3 \mathrm{~nm}$ sized gold nanoparticles (AuNPs) encapsulated by hexanethiol on a flat Poly Vinyl Phenol (PVP) layer supported on PI/Glass, before imprinting with a PDMS stamp at $40 \mathrm{KPa}$ and $80^{\circ} \mathrm{C}$ for $30 \mathrm{~min}$. A final stabilization at 140 ${ }^{\circ} \mathrm{C}$ for 10 min yielded gold-based patterns with following dimension: width $750 \mathrm{~nm}$, pitch $4 \mu \mathrm{m}$ for micro wires, diameter $4.5 \mu \mathrm{m}$, pitch $8 \mu \mathrm{m}$ for micro holes and width $2 \mu \mathrm{m}$ and pitch $8 \mu \mathrm{m}$ for microdots structures. More recently, Visser et al, ${ }^{48}$ prepared $\mathrm{TiO}_{2}$ Mie resonators on $\mathrm{Si}$ and glass substrates from a colloidal dispersion of anatase and rutile $\mathrm{TiO}_{2} \mathrm{NPs}(\sim 50 \mathrm{~nm}$ in diameter). First, a drop of the suspension was dispersed on the substrate surface and then the PDMS mold was pressed down at $100 \mathrm{~g} / \mathrm{cm}^{2}$ and at $100{ }^{\circ} \mathrm{C}$ until the NPs solution was dried out. Finally, PDMS stamp was peeled-off to obtain patterns with the compact $\mathrm{TiO}_{2}$ NPs as shown in Figure 8.
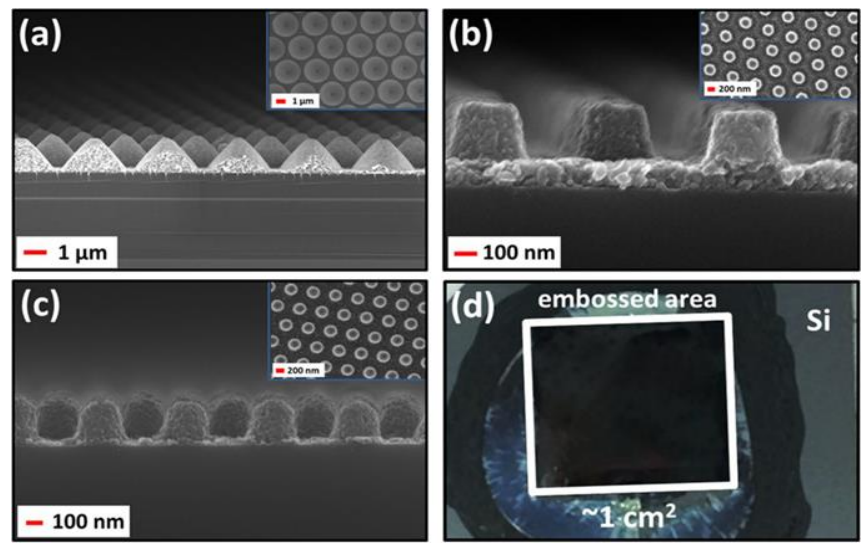

Figure 8. Scanning electron microscopy (SEM) images of the fabricated $\mathrm{TiO}_{2} \mathrm{NP}$-based optical coatings on Si. Cross-section SEM images of the embossed (a) parabolic microcone array, (b) nanodisk-1 array, and (c) nanodisk-2 array structures on Si. The top view SEM images are included as insets. (d) Camera top view image of the typical embossing area $\left(\sim 1 \mathrm{~cm}^{2}\right)^{48}$. Reprinted with permission from [Visser, D.; Chen, D. Y.; Désières, Y.; Ravishankar, A. P.; Anand, S. Embossed Mie Resonator Arrays Composed of Compacted TiO2 Nanoparticles for Broadband Anti-Reflection in Solar Cells. Sci. Rep. 2020, 10 (1), 12527. https://doi.org/10.1038/s41598-020-69518-6], open-access attribution 4.0 International (CC BY 4.0) license, Copyright 2020, NATURE, SCIENTIFIC REPORTS.

\subsubsection{Pressure T-NIL from hybrid (organic/inorganic) resins}

The T-NIL process has been studied with different metal oxides $\left(\mathrm{Al}_{2} \mathrm{O}_{3}, \mathrm{Ga}_{2} \mathrm{O}_{3}, \mathrm{In}_{2} \mathrm{O}_{3}, \mathrm{Y}_{2} \mathrm{O}_{3}, \mathrm{~B}_{2} \mathrm{O}_{3}, \mathrm{TiO}_{2}\right.$, $\mathrm{SnO}_{2}, \mathrm{ZrO}_{2}, \mathrm{GeO}_{2}, \mathrm{HfO}_{2}, \mathrm{Nb}_{2} \mathrm{O}_{5}, \mathrm{Ta}_{2} \mathrm{O}_{5}, \mathrm{~V}_{2} \mathrm{O}_{5}$, and $\mathrm{WO}_{2}$ ) from hybrid formulations by Dinachali et al. ${ }^{38}$ in 2013 and later on by Zhang et $\mathrm{al}^{49}$ in 2017 . The resists were prepared by mixing corresponding metal alkoxides with 2-(methacryloyloxy) ethyl acetoacetate (MAEAA) as a chelating agent and ethylene glycol dimethacrylate (EDMA) as cross-linker and BPO (Benzoyl peroxide). The solution was deposited by spin coating on Si wafers and NIL was performed with a PDMS mold under 30 bar and at $110^{\circ} \mathrm{C}$ - to $130{ }^{\circ} \mathrm{C}$ for $15 \mathrm{~min}-5 \mathrm{~h}$, depending on the oxide. After demolding, patterns were annealed between $300-475{ }^{\circ} \mathrm{C}$ for 1 $2 \mathrm{~h}$. Typical characteristics are reported in Table 4. As expected with sol-gel molecular inorganic precursors 
and with such a high content of stabilizing agents, a relatively high shrinkage accompanies the final annealing. The reason for the fluctuation in shrinkage is likely attributed to the difference in organic content used for each metal oxide and to the difference in coordination degree of each metal, allowing more or less coordinating solvent molecules prior to thermal curing.

Table 4. Summary of the approximate feature size reduction at every step of the imprinting of various oxides with a $250 \mathrm{~nm}$ grating mold (aspect ratio $=1$ ) using the chelated monomer route. The imprinted patterns were subjected to isothermal heat-treatment ${ }^{38}$. Reprinted with permission from [Dinachali, S. S.; Saifullah, M. S. M.; Ganesan, R.; Thian, E. S.; He, C. A Universal Scheme for Patterning of Oxides via Thermal Nanoimprint Lithography. Adv. Funct. Mater. 2013, 23 (17), 2201-2211], copyright 2013, JOHN WILEY AND SONS, ADVANCED FUNCTIONAL MATERIALS.

\begin{tabular}{|c|c|c|c|c|c|c|}
\hline Resist & \multicolumn{2}{|c|}{$\begin{array}{c}\text { Feature size of the imprint } \\
\text { after thermal polymerization }\end{array}$} & $\begin{array}{c}\text { Heat - } \\
\text { treatment } \\
\text { conditions }\end{array}$ & $\begin{array}{l}\text { Oxide feature size after the } \\
\text { heat-tratement of imprinted } \\
\text { structures }\end{array}$ & $\begin{array}{c}\text { Total feature size } \\
\text { reduction with } \\
\text { respect to mold } \\
\text { feature size [\%] }\end{array}$ \\
\hline & $\begin{array}{l}\text { Width of } \\
\text { imprint [nm] }\end{array}$ & $\begin{array}{l}\text { Feature size } \\
\text { reduction [\%] }\end{array}$ & $\begin{array}{l}\text { Width of the } \\
\text { oxide feature } \\
\text { [nm] }\end{array}$ & $\begin{array}{l}\text { Feature } \\
\text { size } \\
\text { reduction } \\
{[\%]}\end{array}$ & \\
\hline $\mathrm{WO}_{3}$ & 175 & $30 \%$ & $450^{\circ} \mathrm{C}$ for $1 \mathrm{~h}$ & - & - & - \\
\hline $\mathrm{SnO}_{2}$ & 170 & $32 \%$ & $450^{\circ} \mathrm{C}$ for $1 \mathrm{~h}$ & 165 & $3 \%$ & $34 \%$ \\
\hline $\mathrm{B}_{2} \mathrm{O}_{3}$ & 200 & $20 \%$ & $300^{\circ} \mathrm{C}$ for $3 \mathrm{~h}$ & 150 & $25 \%$ & $40 \%$ \\
\hline $\mathrm{In}_{2} \mathrm{O}_{3}$ & 185 & $26 \%$ & $300^{\circ} \mathrm{C}$ for $1 \mathrm{~h}$ & 130 & $30 \%$ & $48 \%$ \\
\hline $\mathrm{V}_{2} \mathrm{O}_{5}$ & 131 & $48 \%$ & $375^{\circ} \mathrm{C}$ for $1.5 \mathrm{~h}$ & 115 & $12 \%$ & $54 \%$ \\
\hline $\mathrm{ZrO}_{2}$ & 147 & $41 \%$ & $400^{\circ} \mathrm{C}$ for $1.5 \mathrm{~h}$ & 65 & $56 \%$ & $74 \%$ \\
\hline $\mathrm{Nb}_{2} \mathrm{O}_{5}$ & 176 & $30 \%$ & $475^{\circ} \mathrm{C}$ for $1 \mathrm{~h}$ & 57 & $68 \%$ & $77 \%$ \\
\hline $\mathrm{Ta}_{2} \mathrm{O}_{5}$ & 197 & $21 \%$ & $450^{\circ} \mathrm{C}$ for $1 \mathrm{~h}$ & 58 & $71 \%$ & $77 \%$ \\
\hline $\mathrm{HfO}_{2}$ & 194 & $22 \%$ & $450^{\circ} \mathrm{C}$ for $1 \mathrm{~h}$ & 55 & $72 \%$ & $78 \%$ \\
\hline $\mathrm{GeO}_{2}$ & 162 & $35 \%$ & $350^{\circ} \mathrm{C}$ for $1 \mathrm{~h}$ & 53 & $67 \%$ & $79 \%$ \\
\hline $\mathrm{Y}_{2} \mathrm{O}_{3}$ & 165 & $34 \%$ & $450^{\circ} \mathrm{C}$ for $1 \mathrm{~h}$ & 49 & $70 \%$ & $80 \%$ \\
\hline $\mathrm{Ga}_{2} \mathrm{O}_{3}$ & 200 & $20 \%$ & $450^{\circ} \mathrm{C}$ for $1.5 \mathrm{~h}$ & 43 & $79 \%$ & $83 \%$ \\
\hline $\mathrm{TiO}_{2}$ & 171 & $32 \%$ & $450^{\circ} \mathrm{C}$ for $1 \mathrm{~h}$ & 40 & $77 \%$ & $84 \%$ \\
\hline
\end{tabular}

\subsubsection{Pressure T-NIL from sol-gel solutions}

In 2017, Zhang et al. ${ }^{49}$ reported T-NIL of sol-gel ZnO on large surfaces. The solution was prepared by dissolving Zinc acetate 2-hydrate $\left(\mathrm{Zn}\left(\mathrm{CH}_{3} \mathrm{COO}\right)_{2} \cdot 2 \mathrm{H}_{2} \mathrm{O}\right)$ in $\mathrm{N}, \mathrm{N}$-dimethylformamide (DMF) solvent in presence of chelating diethanolamine (DEA). The $\mathrm{ZnO}$ sol was spin-coated on 8-inch polyimide substrate (PI) and imprinted with a PDMS mold under $0.6 \mathrm{MPa}$ pressure and $250{ }^{\circ} \mathrm{C}$ for $2 \mathrm{~h}$, followed by annealing in air at $250{ }^{\circ} \mathrm{C}$ for $2 \mathrm{~h}$. The final dimension of the nano-hole arrays was obtained with a diameter of 800 $\mathrm{nm}$ and depth of $200 \mathrm{~nm}$. The size reduction in the z-direction (depth) of pillars was observed from $400 \mathrm{~nm}$ (depth of pillars from master) to $200 \mathrm{~nm}$ (depth of the replicated pillars). At such a relatively low temperature, organic linkers were not fully eliminated.

Grating pattern molds were used to obtain square patterns of silica by two steps of hot embossing. Peroz et al. in $2009^{27}$ and Letailleur et al. in $2010^{50}$ used a simple sol-gel formulation prepared by hydrolyzing methyltriethoxysilane (MTEOS) in a hydroalcoholic acidic solution. A $300 \mathrm{~nm}$ thick film was spin-coated on the Si/glass substrate and was first imprinted with a PDMS mold heated at $110^{\circ} \mathrm{C}$ for $240 \mathrm{~s}$ under $<0.2$ MPa pressure. The stamp was then demolded and rotated at $90^{\circ}$ for the second imprinting to take place in the same conditions. Finally, the sample was annealed at $550{ }^{\circ} \mathrm{C}$ for $15 \mathrm{~min}$ to yield amorphous $\mathrm{SiO}_{2}$. The squares patterns had a high aspect ratio of $\sim 4$ (see Figure 9$)^{27}$. 


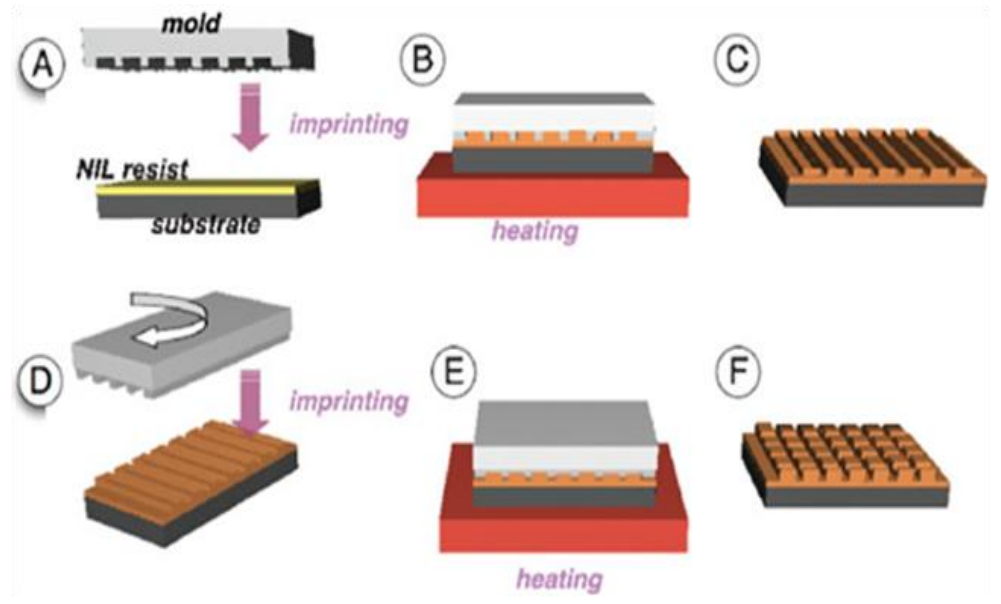

Figure 9. Schematic illustration (A-F) of the NIL imprinting process ${ }^{27}$. Reprinted with permission from [Peroz, C.; Chauveau, V.; Barthel, E.; Søndergård, E. Nanoimprint Lithography on Silica Sol-Gels: A Simple Route to Sequential Patterning. Adv. Mater. 2009, 21 (5), 555-558. https://doi.org/10.1002/adma.200702484], Copyright 2009, JOHN WILEY AND SONS, ADVANCED MATERIALS.

\subsubsection{Pressure T-NIL from NPs dispersion}

Jiang et al in 2013, ${ }^{51}$ reported patterning of $\mathrm{TiO}_{2}$ films with the same two steps T-NIL. Firstly, $\mathrm{TiO}_{2}$ (Degussa P25) dispersion was prepared by mixing $\mathrm{TiO}_{2}$ nanoparticles with ethyl cellulose in anhydrous terpineol and Ethanol. $\mathrm{TiO}_{2} \mathrm{NP}$ films were deposited on FTO glass by Blading machine. The first T-NIL was accomplished by pressing (70 Kg / $0.3 \mathrm{~cm}^{2}$ active area) a Ni stamp at $70{ }^{\circ} \mathrm{C}$ for $10 \mathrm{~min}$ using a commercial nanoimprinting machine. The second imprint used $110^{\circ} \mathrm{C}$ with the pressure of $90 \mathrm{~kg} /$ $0.3 \mathrm{~cm}^{2}$ active area, for $15 \mathrm{~min}$. After annealing at $500{ }^{\circ} \mathrm{C}$ for $30 \mathrm{~min}$ the $\mathrm{TiO}_{2}$ square patterns exhibited 270 $\mathrm{nm}$ depth and $\sim 900 \mathrm{~nm}$ in pitch. The conditions for the second imprint were stronger than the first one to overcome the viscosity loss by the consolidation induced at $70^{\circ} \mathrm{C}$ for $10 \mathrm{~min}$.

\subsection{Direct thermal NIL}

In 2009, Khan et al. ${ }^{52}$ demonstrated the possibility to imprint a sol-gel solution of lead zirconate titanate (PZT) from a sol-gel solution composed of zirconium n-propoxide, titanium isopropoxide, 2methoxyethanol, lead acetate trihydrate, and glacial acetic acid. After spin-casting a layer of this solution on Si wafers, the PDMS mold was applied and dried for 15-30 min at $80{ }^{\circ} \mathrm{C}$. Finally, after demolding and annealing treatment at $650{ }^{\circ} \mathrm{C}$ for $10 \mathrm{~min}$, line grating of $25 \mathrm{~nm}$ height and $380 \mathrm{~nm}$ width were obtained. The aspect ratio (0.07) of the present features could have been increased if pressure was applied to the mold as described in the previous section.

Kothari et al. ${ }^{30}$ prepared Indium Tin Oxide (ITO) and $\mathrm{TiO}_{2}$ nanostructures patterns from combinations of NPs and corresponding organic/inorganic sol-gel binders, using alternative UV or Thermal NIL. The ITO resin was prepared by mixing ITO NP dispersed in n-methyl-2-pyrrolidone (NMP) solvent at $80{ }^{\circ} \mathrm{C}$, and ITO sol composed of tin acetate $\left(\mathrm{Sn}\left(\mathrm{CH}_{3} \mathrm{CO}_{2}\right)_{4}\right.$ and indium nitrate $\left(\mathrm{In}\left(\mathrm{NO}_{3}\right)_{3} \cdot \mathrm{xH}_{2} \mathrm{O}\right)$ dissolved in NMP binder. Thin-film composed either of $100 \%$ NP or $80 \%$ NP $+20 \%$ ITO sol were spin-cast and the PDMS mold was then applied. The composite system was cured at $150^{\circ} \mathrm{C}$ for $30 \mathrm{~s}$ for stiffening while the solvent was pervaporated through the PDMS by aging at room temperature. The demolded patterns were then 
annealed at $500{ }^{\circ} \mathrm{C}$ for $1 \mathrm{~h}$. ITO line grating and square patterns were obtained with a relatively low aspect ratio and low height shrinkage (see table 5).

Table 5. Line Height (LH) and Shrinkage in Feature Height during Imprinting and Heat Treatment Steps for Fabrication of ITO Gratings Using of Different Proportions of ITO NPs and ITO Sol-Gel Precursor ${ }^{30}$. Reprinted with permission from [Kothari, R.; Beaulieu, M. R.; Hendricks, N. R.; Li, S.; Watkins, J. J. Direct Patterning of Robust One-Dimensional, Two-Dimensional, and Three-Dimensional Crystalline Metal Oxide Nanostructures Using Imprint Lithography and Nanoparticle Dispersion Inks. Chem. Mater. 2017, 29 (9), 3908-3918. https://doi.org/10.1021/acs.chemmater.6b05398], Copyright 2017, ACS-CHEMISTRY OF MATERIALS.

\begin{tabular}{|l|l|l|l|}
\hline & $\begin{array}{l}\text { LH of a master } \\
\text { mold }\end{array}$ & $\begin{array}{l}\text { LH/ shrinkage-I (for as-imprinted } \\
\text { sample) }\end{array}$ & $\begin{array}{l}\text { LH/ shrinkage-HT (for 500 }{ }^{\circ} \mathbf{C} \\
\text { heat-treated sample) }\end{array}$ \\
\hline $\mathbf{1 0 0 ~ N P ~ I T O ~}$ & $480 \mathrm{~nm}$ & $380 \mathrm{~nm} / 21 \%$ & $365 \mathrm{~nm} / 4 \%$ \\
\hline $\begin{array}{l}\mathbf{8 0 ~ N P / 2 0} \text { sol } \\
\text { ITO }\end{array}$ & $480 \mathrm{~nm}$ & $385 \mathrm{~nm} / 20 \%$ & $355 \mathrm{~nm} / 8 \%$ \\
\hline
\end{tabular}

The same study was conducted on $\mathrm{TiO}_{2}$ systems using $15 \mathrm{wt} \% \mathrm{TiO}_{2} \mathrm{NP}$ dispersion in NMP and methanol, and titanium diisopropoxide bis-(acetylacetonate) and TPA $\left.\left(\mathrm{CH}_{3}\right)_{2} \mathrm{CHO}\right]_{2} \mathrm{Ti}\left(\mathrm{C}_{5} \mathrm{H}_{7} \mathrm{O}_{2}\right)_{2}$, in isopropanol. The imprinting curing was conducted at $120{ }^{\circ} \mathrm{C}$ for $15 \mathrm{~s}$, and the final thermal treatment occurs at $500{ }^{\circ} \mathrm{C}$ for 1 $\mathrm{h}$. The obtained line gratings are shown in Figure 10 and the corresponding relative shrinkage is given in Table 6. As already observed with Silica systems in the previous part, the latter studies on ITO and $\mathrm{TiO}_{2}$ confirmed the advantage of using NP sources to reduce shrinkage.
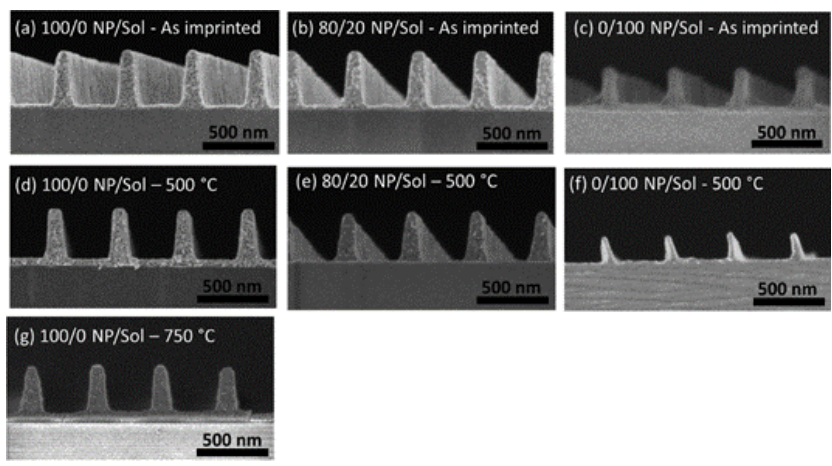

Figure 10. Cross-section SEM images of patterned $\mathrm{TiO}_{2}$ gratings imprinted with inks having different ratios of $\mathrm{TiO}_{2}$ NPs and sol of $\mathrm{TiO}_{2}$. (a-c) As-imprinted gratings: (a) $100 \mathrm{NP}$, (b) $80 \mathrm{NP} / 20$ sol, and (c) 100 sol (d-f) Gratings upon calcination at $500^{\circ} \mathrm{C}$ for $3 \mathrm{~h}$ : (d) $100 \mathrm{NP}$, (e) $80 \mathrm{NP} / 20 \mathrm{sol}$, and (f) $100 \mathrm{sol}$. (g) $100 \mathrm{NP}$ grating pattern upon calcination at $750{ }^{\circ} \mathrm{C}$ for $3 \mathrm{~h}^{30}$. Reprinted with permission from [Kothari, R.; Beaulieu, M. R.; Hendricks, N. R.; Li, S.; Watkins, J. J. Direct Patterning of Robust One-Dimensional, TwoDimensional, and Three-Dimensional Crystalline Metal Oxide Nanostructures Using Imprint Lithography and Nanoparticle Dispersion Inks. Chem. Mater. 2017, 29 (9), 3908-3918. https://doi.org/10.1021/acs.chemmater.6b05398], Copyright 2017, ACS-CHEMISTRY OF MATERIALS. 
Table 6. Line Height (LH) and Shrinkage in Feature Height during Imprinting and Heat Treatment Steps for Fabrication of $\mathrm{TiO}_{2}$ Gratings composed of different proportions of $\mathrm{TiO}_{2} \mathrm{NPs}$ and $\mathrm{TiO}_{2}$ sol solution ${ }^{30}$. [Reprinted with permission from [Kothari, R.; Beaulieu, M. R.; Hendricks, N. R.; Li, S.; Watkins, J. J. Direct Patterning of Robust One-Dimensional, Two-Dimensional, and Three-Dimensional Crystalline Metal Oxide Nanostructures Using Imprint Lithography and Nanoparticle Dispersion Inks. Chem. Mater. 2017, 29 (9), 3908-3918. https://doi.org/10.1021/acs.chemmater.6b05398], Copyright 2017, ACSCHEMISTRY OF MATERIALS.

\begin{tabular}{|c|c|c|c|}
\hline & LH of a master mold & $\begin{array}{l}\text { LH/ shrinkage-I (for as- } \\
\text { imprinted sample) }\end{array}$ & $\begin{array}{lrr}\text { LH/ } & \text { shrinkage-HT (for } \\
500 & { }^{\circ} \mathrm{C} & \text { heat-treated } \\
\text { sample) } & \end{array}$ \\
\hline $100 \mathrm{NP}^{\mathrm{TiO}}{ }_{2}$ & $480 \mathrm{~nm}$ & $385 \mathrm{~nm} / 20 \%$ & $360 \mathrm{~nm} / 6 \%$ \\
\hline $80 \mathrm{NP} / 20$ sol $\mathrm{TiO}_{2}$ & $480 \mathrm{~nm}$ & $340 \mathrm{~nm} / 11 \%$ & $340 \mathrm{~nm} / 11 \%$ \\
\hline $100 \mathrm{Sol} \mathrm{TiO}_{2}$ & $480 \mathrm{~nm}$ & $140 \mathrm{~nm} / 48 \%$ & $140 \mathrm{~nm} / 48 \%$ \\
\hline
\end{tabular}

Using a $\mathrm{TiO}_{2}$ nanoparticle dispersion in 1,2-propanediol and methanol, similar imprinting conditions were then used by $\mathrm{Li}$ et al. in $2018{ }^{53}$ to elaborate $3 \mathrm{D} \mathrm{TiO}_{2}$ woodpiles electrodes by applying several cycles of the following step: (i) imprinting $\mathrm{TiO}_{2}$, (ii) curing in UV-Ozone, (iii) infiltration and planarization with $\mathrm{NOA60}$, (iv) UV-curing of NOA60. After obtaining the desired number of layers, the whole structure was calcined at $750^{\circ} \mathrm{C}$ and was composed of up to 6 layers of pilled rods exhibiting each an aspect ratio of 1 . The 3D structure enables the development of a high specific surface and high accessibility for efficient charge transfer (see Figure 11).

A)

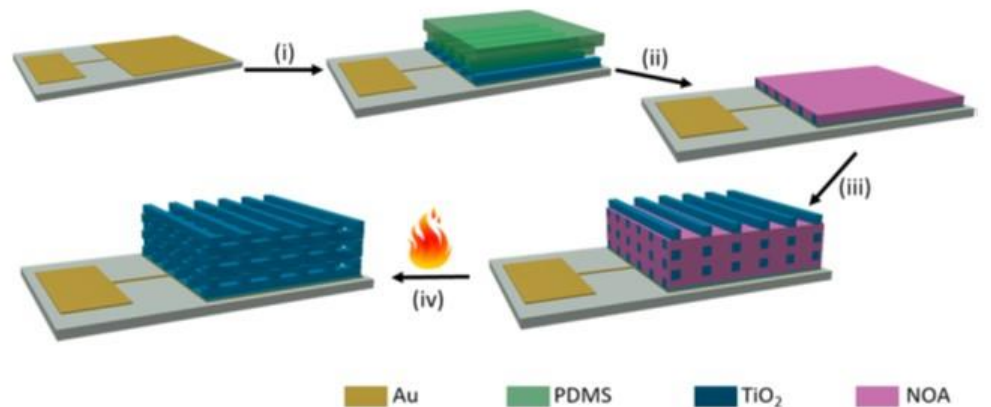

B)

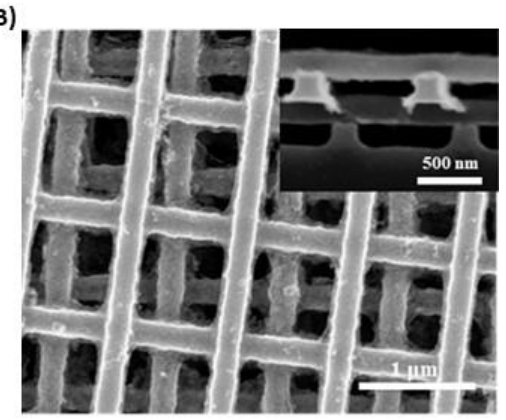

Figure 11. A) Scheme illustrating the method to elaborate woodpile structured by NIL. B) SEM top view and profile images of imprinted structures corresponding to the 6 layers of woodpile structures, prepared by $\mathrm{NIL}^{53}$. Reprinted with permission from [Li, W.; Zhou, Y.; Howell, I. R.; Gai, Y.; Naik, A. R.; Li, S.; Carter, K. R.; Watkins, J. J. Direct Imprinting of Scalable, High-Performance Woodpile Electrodes for ThreeDimensional Lithium-Ion Nanobatteries. ACS Appl. Mater. Interfaces 2018, 10 (6), 5447-5454. https://doi.org/10.1021/acsami.7b14649], Copyright 2018, ACS- APPLIED MATERIALS AND INTERFACES. 
The same year, the same authors reported the formation of patterned LMO electrodes from $\mathrm{LiMn}_{2} \mathrm{O}_{4}$ nanoparticle dispersions in a mixture of 4-hydroxybenzoic acid, N-methyl-2-pyrrolidone, and methanol ${ }^{54}$. After spin coating on ITO glass, imprinting with PDMS molds at $70^{\circ} \mathrm{C}$, and curing at $400^{\circ} \mathrm{C}$ after demolding, features with dimensions ranging from $400 \mathrm{~nm}$ to $2000 \mathrm{~nm}$, and aspect ratio up to 4, were reported.

\subsection{Vapor Pressure Thermal NIL}

An alternative approach to pressing the mold on the resin soft layer to trigger cavity infiltration is to maintain the resin as liquid as possible with a volatile compound (the solvent phase) and pump it through the mold. In fact, PDMS molds being slightly microporous, a pre-degassing of the latter before the application is sufficient to allow this pumping as mentioned in the Generality part. Using a volatile solvent compound as a fluidizer requires to be able to prevent total evaporation from the resin by applying a proper vapor pressure in the chamber before applying the degassed mold. Dalstein et al. ${ }^{55}$ used such degassed PDMS molds to imprint $\mathrm{TiO}_{2}$ from an extremely simple sol-gel formulation composed of $\mathrm{TiCl}_{4}, \mathrm{H}_{2} \mathrm{O}$, and Ethanol with a respective molar ratio of 1/6/50. After deposition of the sol-gel layer on Si or glass substrates, the degassed mold was gently applied on it and maintained at $110{ }^{\circ} \mathrm{C}$ for $5 \mathrm{~min}$ before demolding. Annealing at $450{ }^{\circ} \mathrm{C}$ for $5 \mathrm{~min}$ ensures the complete densification and crystallization of $\mathrm{TiO}_{2}$ into anatase. The $100 \mathrm{~nm}$ motifs

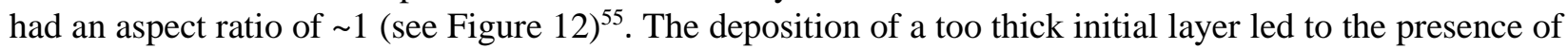
a $200 \mathrm{~nm}$-thick residual layer. The same authors reproduced this method to elaborate patterned surfaces for controlled wetting ${ }^{56}$ and $250 \mathrm{~nm} \mathrm{TiO}_{2}$ dielectric Mie resonator pillar arrays (aspect ratio 1$)^{57}$ with a residual layer as thin as $10 \mathrm{~nm}$ by applying a thinner initial sol-gel layer (see Figure 13). Chen et al. ${ }^{58}$ reported the fabrication of ultrathin $\mathrm{GaAs}$ solar cells with a $\mathrm{TiO}_{2} / \mathrm{Ag}$ nanostructured back mirror using the same procedure. The lack of stabilizing and fluidizing organic agents led to less shrinkage than in the previous methods involving sol-gel precursors. 
(a)
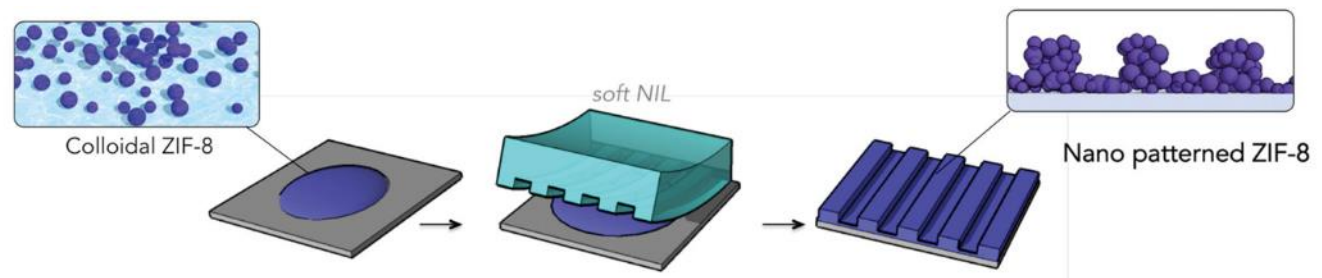

(b)
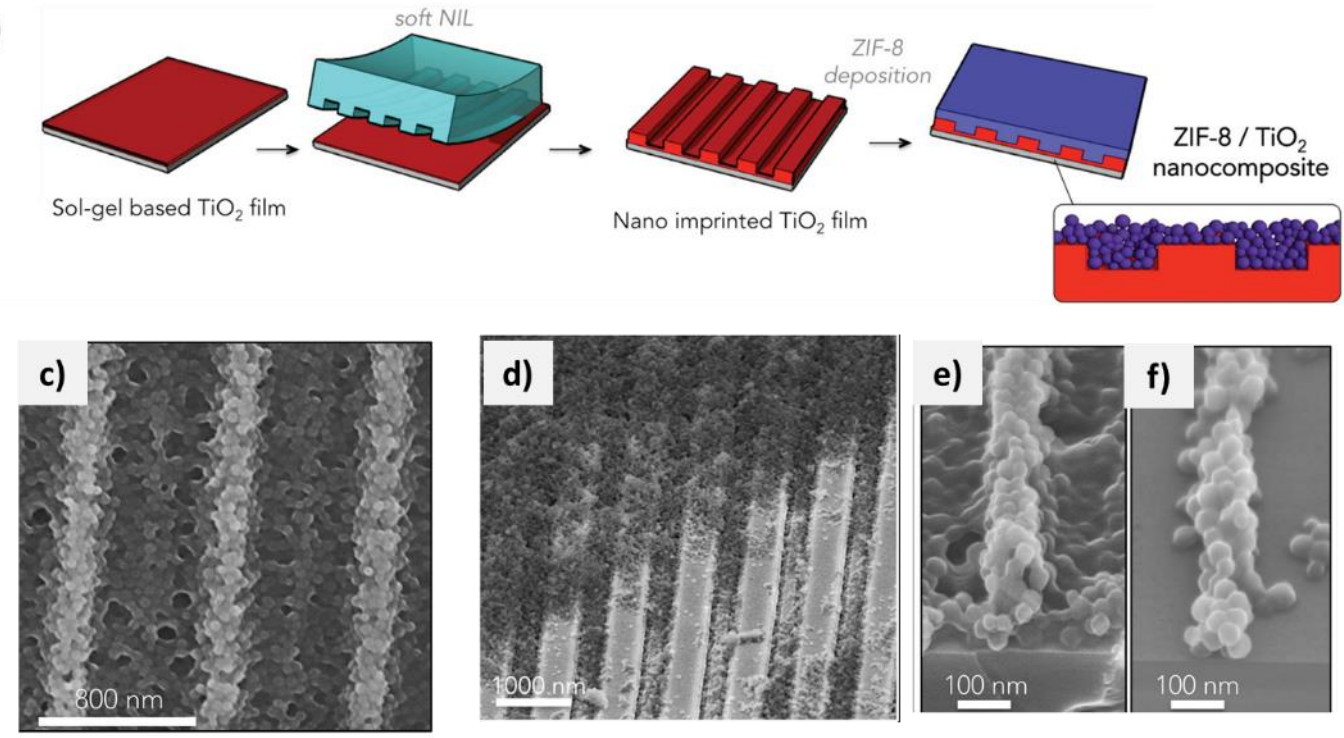

Figure 12. Soft Lithography approaches for both approaches routes (a) nano-patterned ZIF-8 and (b) ZIF8/TiO ${ }_{2}$. SEM image of nano-patterned (c) ZIF-8 (d) scratched zone exhibiting both ZIF-8 covered and uncovered $\mathrm{TiO}_{2}$ Cross-section SEM of nano-patterned ZIF-8 (e) with (f) without residual layer ${ }^{55}$. Reprinted with permission from [Dalstein, O.; Ceratti, D. R.; Boissière, C.; Grosso, D.; Cattoni, A.; Faustini, M. Nanoimprinted, Submicrometric, MOF-Based 2D Photonic Structures: Toward Easy Selective Vapors Sensing by a Smartphone Camera. Adv. Funct. Mater. 2016, 26 (1), 81-90], Copyright 2016, JOHN WILEY AND SONS, ADVANCED FUNCTIONAL MATERIALS. 


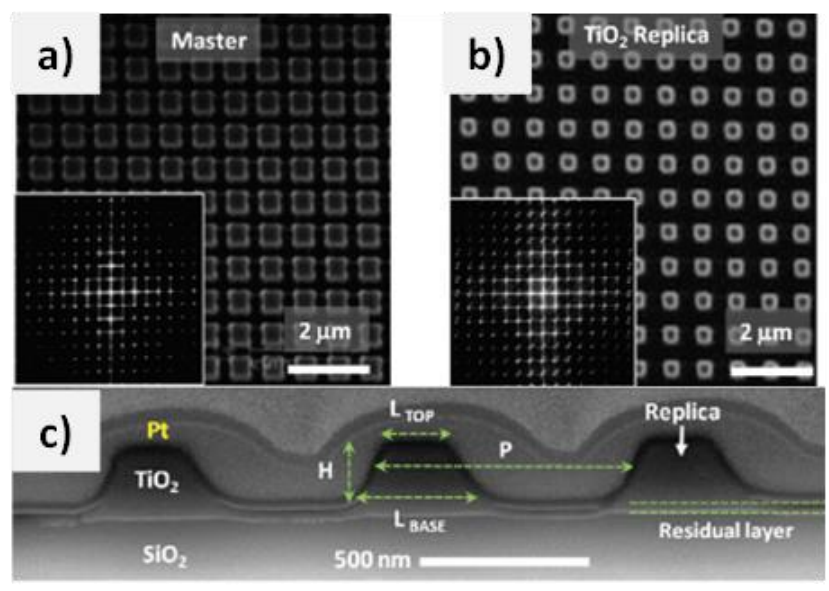

Figure 13. SEM image of a) master, b) replicated $\mathrm{TiO}_{2}$, c) cross-section nanopatterns $\mathrm{TiO}_{2}$ indication the thin residual layer ${ }^{57}$. Reprinted with permission from [Bottein, T.; Wood, T.; David, T.; Claude, J. B.; Favre, L.; Berbézier, I.; Ronda, A.; Abbarchi, M.; Grosso, D. "Black" Titania Coatings Composed of Sol-Gel Imprinted Mie Resonators Arrays. Adv. Funct. Mater. 2017, 27 (2), 1604924. https://doi.org/10.1002/adfm.201604924], Copyright 2017, JOHN WILEY AND SONS, ADVANCED FUNCTIONAL MATERIALS.

The imprinting was performed in a clean room, where temperature and humidity were kept constant. Imprinting outside the cleanroom was accompanied by a loss of reproducibility attributed to changes in the atmospheric humidity. A full study of the influence of humidity on replication quality was then performed with various metal oxides from metal chlorine, water-ethanol solutions by Bottein et al. ${ }^{59}$.

He demonstrated that the faithfulness of the replication of sol-gel systems $\left(\mathrm{TiO}_{2}\right.$, mesoporous $\mathrm{SiO}_{2}$, Methyl$\mathrm{SiO}_{2}, \mathrm{Al}_{2} \mathrm{O}_{3}, \mathrm{Y}-\mathrm{ZrO}_{2}$ ) can be optimized by simply adjusting relative humidity within specific spam during the NIL process, which depends on the external temperature. Initial sol-gel solutions were respectively composed of $1 \mathrm{TiCl}_{4}: 40 \mathrm{EtOH}: 7 \mathrm{H}_{2} \mathrm{O} ; 1 \mathrm{TEOS}: 40 \mathrm{EtOH}: 10 \mathrm{H}_{2} \mathrm{O}: 0.01 \mathrm{HCl}: 0.01 \mathrm{CTAB} ; 0.5 \mathrm{TEOS}$ : $0.5 \mathrm{MTEOS}: 40 \mathrm{EtOH}: 10 \mathrm{H}_{2} \mathrm{O}: 0.01 \mathrm{HCl} ; \mathrm{Al}(\mathrm{OiPr})_{3}: 29 \mathrm{EtOH}: 4.8 \mathrm{H}_{2} \mathrm{O}: 1.4 \mathrm{HCl}: 4:$ and $0.94 \mathrm{Zr}(\mathrm{Cl})_{4}$ : $0.06 \mathrm{Y}\left(\mathrm{NO}_{3}\right)_{3}, 2 \mathrm{H}_{2} \mathrm{O}: 41 \mathrm{EtOH}: 12 \mathrm{H}_{2} \mathrm{O}$ (molar ratios). Straight after deposition by dip-coating, the solgel layers were imprinted with a degassed PDMS mold at $22{ }^{\circ} \mathrm{C}$ in different relative humidity ranging from 20 to $85 \%$, before undergoing consolidation for $5 \mathrm{~min}$ at $120{ }^{\circ} \mathrm{C}$ and final annealing at $450{ }^{\circ} \mathrm{C}$ for $10 \mathrm{~min}$ after demolding. Figure 13 shows that for the $\mathrm{TiO}_{2}$ system, a too low humidity led to no, or low aspect-ratio, replicas, while at too high humidity a dramatic loss of homogeneity is obtained. The best replication (homogeneous and high aspect ratio) was achieved with $\sim 60 \% \mathrm{RH}$ at $22{ }^{\circ} \mathrm{C}$ for $\mathrm{TiO}_{2}$. Others systems did not show the same dependency and a systematic investigation of the quantity of water up-taken into the asprepared sol-gel initial layers with respect to $\mathrm{RH}$ was undertaken by environmental ellipsometry (see Figure 14). The deduction was that even if the optimal $\mathrm{RH}$ is different for each metal oxide system, optimal water content of $30 \%$ volume in the films is common to all the cases, which is related to the difference in hygroscopic property of the as-prepared films. Furthermore, in absence of a stabilizer, the sol-gel tends to spontaneously cross-link with time, which needs to be taken into account ${ }^{59}$. 

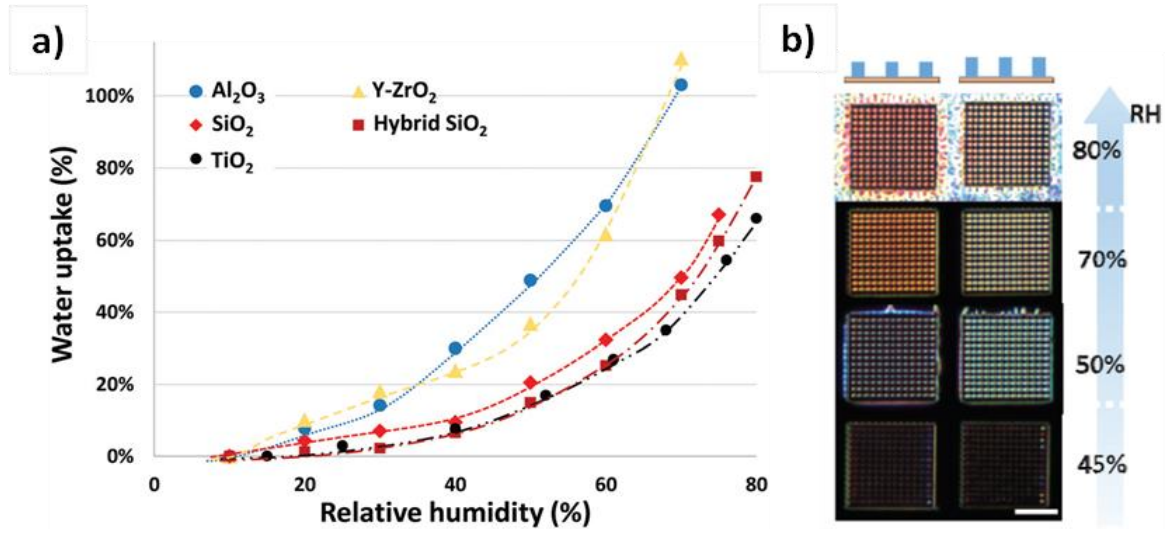

Figure 14. (a) Water uptake of various as-prepared xerogels with respect to relative humidity measured by in situ time-resolved Ellipsometry. (b) Optical microscopy dark-field images of $\mathrm{TiO}_{2}$ replicas imprinted at 45\%, 50\%, 70\% and 80\% RH, replicated ${ }^{59}$. Reprinted with permission from [Bottein, T.; Dalstein, O.; Putero, M.; Cattoni, A.; Faustini, M.; Abbarchi, M.; Grosso, D. Environment-Controlled Sol-Gel Soft-NIL Processing for Optimized Titania, Alumina, Silica and Yttria-Zirconia Imprinting at Sub-Micron Dimensions. Nanoscale 2018, 10 (3), 1420-1431. https://doi.org/10.1039/C7NR07491C], Copyright 2018, ROYAL SOCIETY OF CHEMISTRY. 
The latter method was then exploited by Naffouti et al. ${ }^{60}$ and Checcucci et al ${ }^{61}$ in 2019 to prepare high aspect ratio pillar arrays as optical metamaterials, and by Modaresialam et al. ${ }^{62}$ in 2020 to imprint broadband, wide-angle, robust anti-reflection coatings on $10 \mathrm{~cm}$ wafers (see Figure 15).
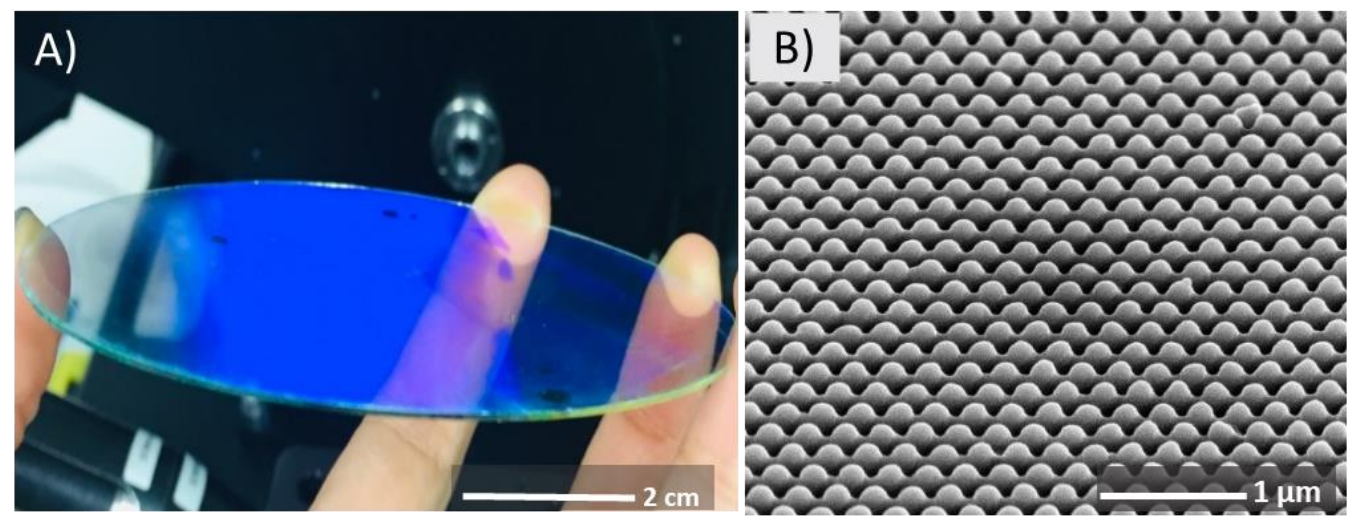

\section{C)}
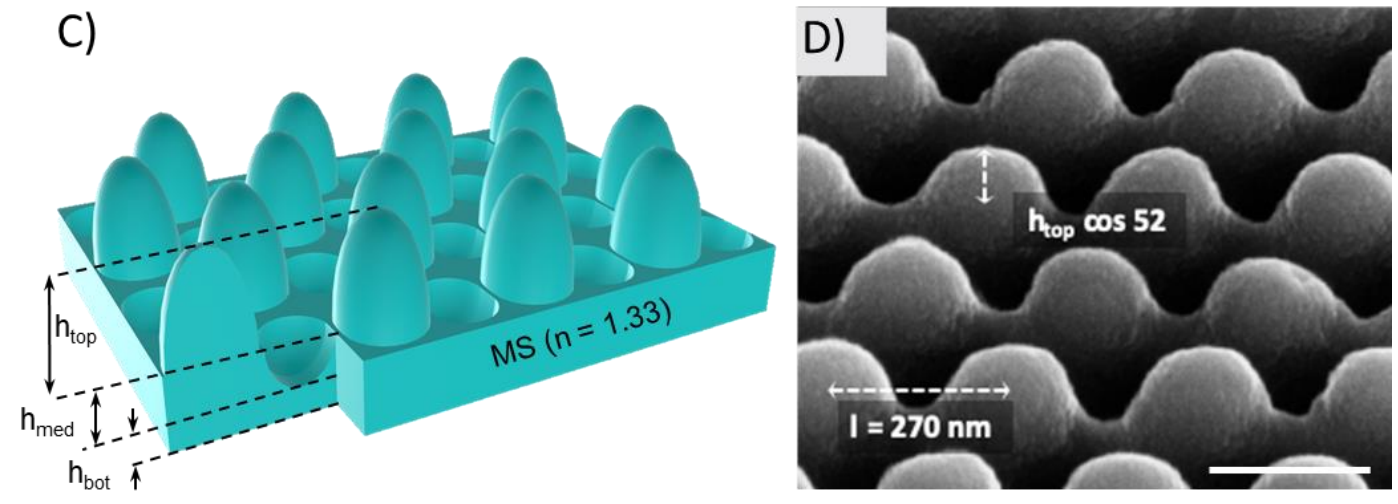

Figure 15. A) Picture of a $10 \mathrm{~cm}$ diameter wafer coated with the nanoimprinted methylated silica $\mathrm{SiO}_{2}$ (B,D) Scanning electron microscopy (SEM) image (C) Scheme illustrating the topography of the nippledimple surface ${ }^{62}$. Reprinted with permission from [Bochet-Modaresialam, M.; Claude, J.-B.; Grosso, D.; Abbarchi, M. Methylated Silica Surfaces Having Tapered Nipple-Dimple Nanopillar Morphologies as Robust Broad-Angle and Broadband Antireflection Coatings. ACS Appl. Nano Mater. 2020, 3 (6), 52315239. https://doi.org/10.1021/acsanm.0c00646], Copyright 2020, ACS- APPLIED NANOMATERIALS.

\section{Direct printing}

Printing by soft-NIL without UV and thermal-induced cross-linking cannot be performed with any systems. Sol-gel silica is however well adapted as its condensation rate is relatively slow when in solution but can become extremely fast upon evaporation of the solvent owing to a spatial gathering of the silica moieties. Therefore, one needs to make sure that the sol-gel initial layer is soft enough for the impregnation in the mold and cross-link after infiltration whatever the time needed to maintain the structure when demolding. In 2011, A. Polman's group ${ }^{63}$ used simple silica sol-gel formulations composed of methyl-tri-methoxysilane, tetra-methoxy-ortho-silicate, formic acid, water, and propanol as a solvent, that they deposited and imprinted directly with PDMS stamps. Demolding was possible after $20 \mathrm{~min}$ without heat to yield $400 \mathrm{~nm}$ square arrays after further annealing at $200{ }^{\circ} \mathrm{C}$ (shrinkage 18\%). The presence of a methyl group on the silica precursor is crucial to slow down the condensation and enable infiltration. In 2017, Shin et al. ${ }^{64}$ 
prepared piezoelectric nano-generators via Imprinting Sol-Gel Fe doped $\mathrm{BaTiO}_{3}$ nano-pillars. In this work, the sol-gel solution was synthesized using barium hydroxide $\mathrm{Ba}(\mathrm{OH})_{2} \cdot 8 \mathrm{H}_{2} \mathrm{O}$, titanium butoxide and iron nitrate $\mathrm{FeNO}_{3} \cdot 9 \mathrm{H}_{2} \mathrm{O}$ as starting materials. The molar ratio between materials was Ba:Ti:Fe = 1:0.98:0.02. The $\mathrm{BaTiO}_{3}$ sol-gel layer was then poured on the pre-cleaned ITO surface, followed by covering with a PDMS mold with a nanohole array. After aging, the PDMS stamp was removed, leaving fragile hexagonal pillars that needed final curing under UV $\left(80 \mathrm{~mW} / \mathrm{cm}^{2}, \sim 365 \mathrm{~nm}\right)$ for $2.5 \mathrm{~min}$. Then features with a diameter of $\sim 120 \mathrm{~nm}$, the pitch of $400 \mathrm{~nm}$, and height of $\sim 400 \mathrm{~nm}$ were obtained.

\section{Applications}

Thanks to its versatility in framing different materials in a wide range of 3D structures size and shape on arbitrary substrates (e.g. glass, semiconductor, metal, plastic), NIL has been efficiently exploited for a plethora of applications, ranging from light management, electronics, and biology. Here we briefly review some of the major contributions of NIL in photonic-crystals, solar cells, anti-reflection coatings and biology.

\subsection{Photonic Crystals}

Photonic crystals (PhCs) are periodic structures, typically made of high permittivity materials, widely employed for light management. They can be used to enhance light absorption (e.g atop a silicon based photovoltaic device) or light extraction from a bulk material (e.g. atop of a LED), integrated circuits (e.g. guiding light on a photonic chip for information processing), confine light in small volumes (e.g. for lasing), beam steering (e.g. for light coupling in an optical fiber). NIL is a powerful tool for texturing a material modifying its properties for light manipulation. This approach has been successfully exploited in this field being a high throughput and low-cost technique.

At the beginning of the $21^{\text {st }}$ century, PhCs based on organic-inorganic material with a high refractive index $(\mathrm{n} \sim 1.63$ at $633 \mathrm{~nm})$ were developed with a novel NIL approach ${ }^{65}$. These periodic nanostructures were prepared by patterning a thin film of methacryl silica-titania hybrimer via UV NIL. Later on, another type of hybrid nanoparticles/polymer resist composite was proposed ${ }^{39}$. A mixture of $\mathrm{TiO}_{2}$ nanoparticles and photoresist was directly patterned into large areas 3D PhCs via UV-assisted NIL. Figure 16a) illustrates the SEM images of PhCs. The 3D PhC exhibited a photonic bandgap at about $840 \mathrm{~nm}$ (maximum reflectance $\sim 72 \%$ at $840 \mathrm{~nm}$, figure $16 \mathrm{~b}$ ). 

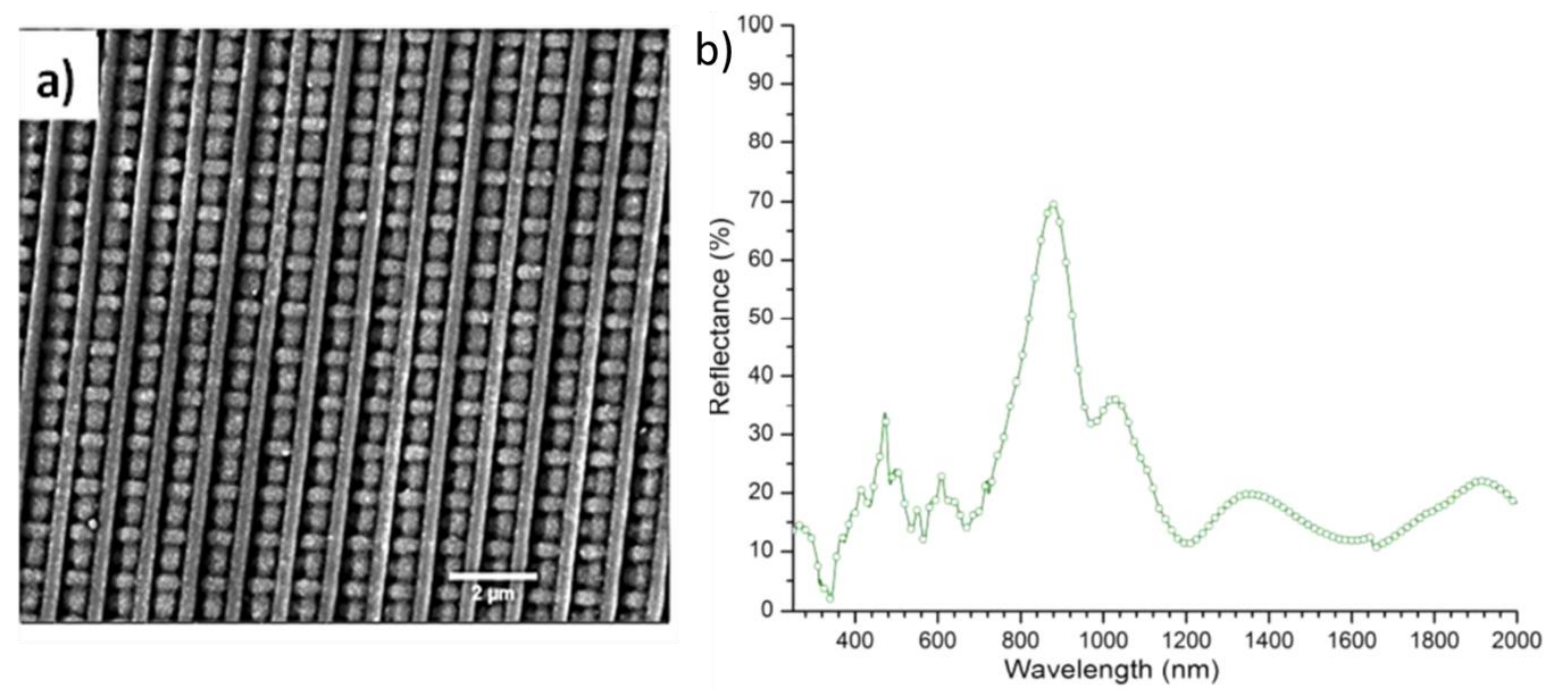

Figure 16. (a) Top-down SEM image of a four-layer 3D photonic structure and (b) UV-vis-NIR specular reflectance measurement at $35^{\circ}$ with respect to the surface normal of a six-layer 3D photonic crystal ${ }^{39}$. Reprinted with permission from [Beaulieu, M. R.; Hendricks, N. R.; Watkins, J. J. Large-Area Printing of Optical Gratings and 3D Photonic Crystals Using Solution-Processable Nanoparticle/Polymer Composites. ACS Photonics 2014, 1 (9), 799-805. https://doi.org/10.1021/ph500078f.] ,Copyright 2014, ACS PHOTONIC.

Moreover, the observed full stop-band in all directions indicates the fabrication of a true 3D PhC. Feedback control for alignment could be in principle used to improve the quality of these structures. This approach has the potential to scale up the technique to larger areas and higher throughputs at low cost by using rollto-roll fabrication.

\subsection{Solar cells}

Photonic structures such as photonic crystals and transparent electrodes find their applications in optoelectronic devices. As an example, we report here some cases relevant to photovoltaic cells. Being a scalable fabrication process, NIL can be in principle extended to large surfaces and fits thus the needs for large solar panels with integrated micro and nano-patterns.

Later on Polman's group reported the fabrication of different types of solar cells configuration by using NIL techniques ${ }^{63,66-68}$. In 2011, Ferry et al. ${ }^{63}$ designed and fabricated periodic and random nano-scatter arrays for solar cells. The patterns were coated by Ag and then, ZnO:Al, ,n-i-p a-Si:H, ITO. The cells consisted of $\mathrm{Ag}$, coating the different nanopatterned silica sol gel of ZnO:Al, n-i-p a-Si:H and ITO. The $400 \mathrm{~nm}$ pitch pattern and the random pattern showed an efficiency of about $9.5 \%$.

The high conductivity of metals has stimulated interest in metal nanowire (NW) networks and meshes as alternatives to ITO. These geometries can be designed to provide improved optoelectronic performance relative to ITO, achieving concurrent improvements in both optical transparency and electrical conductivity. Van de Groep et al. ${ }^{69}$ reported silver nanowires (Ag NWs) as transparent conducting electrodes (TCE). They used $\mathrm{P}_{3} \mathrm{HT}$-PCBM organic solar cells as a model system. The performance parameters for Ag NWs cells were measured and compared with ITO-based reference cells. The efficiency of ITO reference of $3.45 \%$ is higher than for the NWs $\sim 2.7 \%$. However, the measured external quantum efficiency (EQE) show an enhancement for $700<\lambda<900 \mathrm{~nm}$ and $650<\lambda<800 \mathrm{~nm}$ with $500 \mathrm{~nm}$ in comparison with ITO $^{69}$. 
Photocurrent and photoelectrical enhancement in solar cells developed rapidly by using dielectric materials. Extensive research has been done on light trapping in Si thin-film and organic solar cells. However, only a limited number of research groups have worked on light management in CIGSe cells, Light trapping in ultrathin CIGSe cells is challenging because of the required stability of the light-trapping geometry during the high-temperature growth process. Van Lare et al. ${ }^{67}$ reported a new ultra-thin $\mathrm{Cu}$ (In, Ga) $\mathrm{Se}_{2}$ (CIGSe) solar cells by nanoscale dielectric light scattering $\left(\mathrm{SiO}_{2}, \mathrm{TiO}_{2}\right)^{67}$.

Zinc oxide $(\mathrm{ZnO})$ is currently one of the key functional materials in advanced optoelectronic and photonic applications, including photovoltaics, thanks to its high transparency across the solar spectrum and its excellent electrical properties. The external quantum efficiency (EQE) of ZnO-based NIL patterns with PDMS and PEN molds were measured ${ }^{45}$. These measurements showed the lower cell response on the replica stamped with PDMS than with cells replica with PEN stamp ${ }^{43,44}$.

Jiang et al. ${ }^{51}$ reported the 3D patterning of $\mathrm{TiO}_{2} / \mathrm{Ag}$ films in plasmonic dye-sensitized solar cells (DSSCs). The photovoltaic properties of the DSSCs were studied in different configurations: pure $\mathrm{TiO}_{2}$ film, planar $\mathrm{TiO}_{2} / \mathrm{Ag}$ film and $3 \mathrm{D}$ patterned $\mathrm{TiO}_{2} / \mathrm{Ag}$ film (Figure 17 a). The generated conversion efficiency was $4.59 \%$, $5.35 \%$ and $5.69 \%$, respectively ${ }^{51}$. Ultrathin $\mathrm{GaAs}$ solar cells with $\mathrm{TiO}_{2} / \mathrm{Ag}$ nanostructured back mirror achieved an efficiency of $25 \%$ accompanied by a strong enhancement of EQE in the 600-900 nm wavelength range (see Figure $17 \mathrm{~b})^{58}$.

a

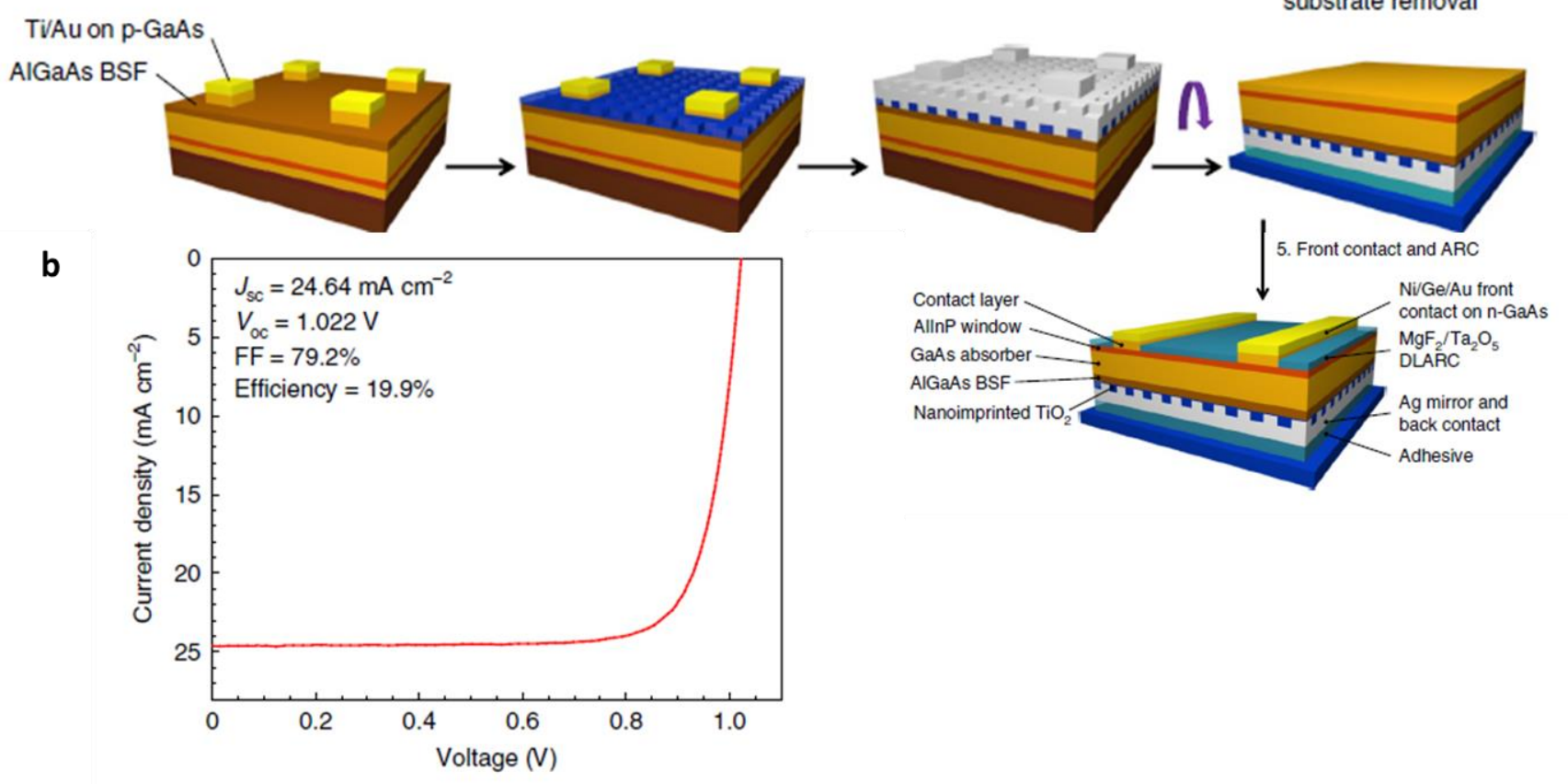


Figure 17. a) Fabrication process for ultrathin GaAs solar cells with a nanostructured back mirror. b) $\mathrm{J}-\mathrm{V}$ characteristics $^{58}$. Reprinted with permission from [Chen, H.-L.; Cattoni, A.; De Lépinau, R.; Walker, A. W.; Höhn, O.; Lackner, D.; Siefer, G.; Faustini, M.; Vandamme, N.; Goffard, J.; Behaghel, B.; Dupuis, C.; Bardou, N.; Dimroth, F.; Collin, S. A 19.9\%-Efficient Ultrathin Solar Cell Based on a 205-Nm-Thick GaAs Absorber and a Silver Nanostructured Back Mirror. Nat. Energy 2019, 4 (9), 761-767. https://doi.org/10.1038/s41560019-0434-y], Copyright 2019, SPRINGER NATURE-NATURE ENERGY.

\subsection{LEDs}

Since $\mathrm{ZnO}$ has the excellent optical and electrical properties, it can be used for transparent electrodes in UV light emitting diodes and laser diodes. In $2012 \mathrm{Jo}$ et al. ${ }^{35}$ reported the fabrication of $\mathrm{ZnO}$ nano particles/resin composite patterned by UV-NIL. The optimization of the refractive index was made by adjusting the NP concentration.

\subsection{Sensors}

In 2016, Dalstein et al. ${ }^{55}$ ZIF-8 MOF-based 2D photonic structures were prepared either by direct T-NIL of ZIF-8 or by its deposition on a $\mathrm{TiO}_{2}$ line array prepared by T-NIL. The $\mathrm{TiO}_{2} / \mathrm{MOF}$ patterned surfaces have been used as diffraction gratings, enabling easy detection of organic solvent vapors by a simple smartphone's camera. The sensing approach is based on the variation of the optical properties of MOF patterns, induced by the selective adsorption of the organic solvent. The comparison of the optical responses reveals that both configurations exhibited similar sensitivity (see Figure 18$)^{55}$.

(a)

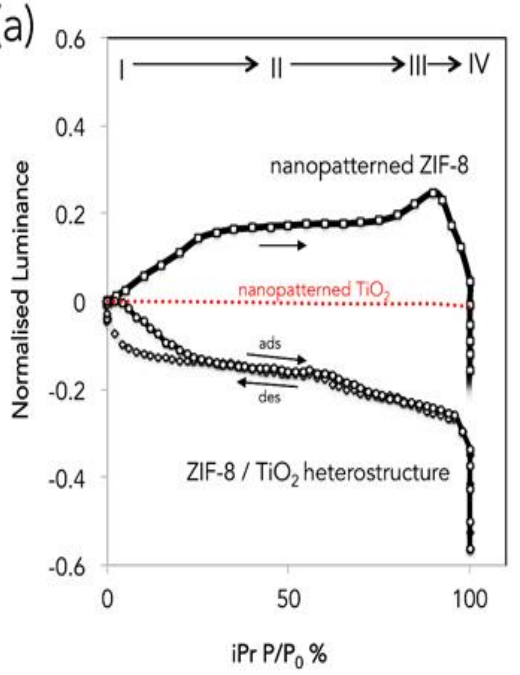

(b)

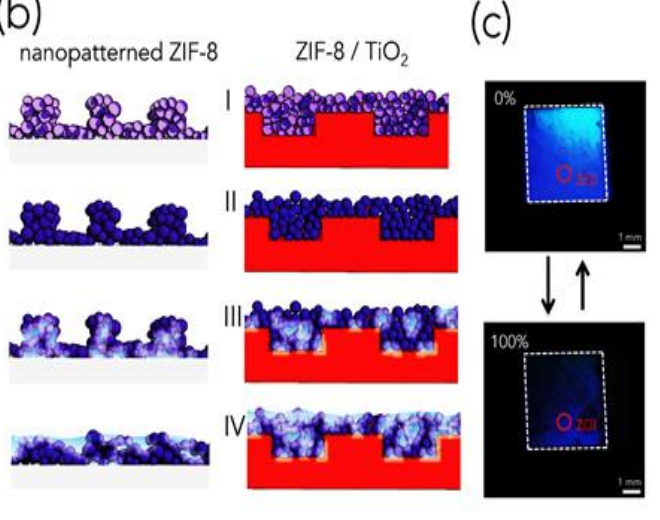

Figure 18. a) Isopropyl alcohol uptake measured by luminance difference; b) illustration of the phenomena taking place during adsorption; c) photographs of the $\mathrm{ZIF}-8 / \mathrm{TiO}_{2}$ hetero-structure ${ }^{55}$. Reprinted with permission from [Dalstein, O.; Ceratti, D. R.; Boissière, C.; Grosso, D.; Cattoni, A.; Faustini, M. Nanoimprinted, Submicrometric, MOF-Based 2D Photonic Structures: Toward Easy Selective Vapors 
Sensing by a Smartphone Camera. Adv. Funct. Mater. 2016, 26 (1), 81-90. https://doi.org/10.1002/adfm.201503016.], Copyright 2016, JOHN WILEY AND SONS, ADVANCED FUNCTIONAL MATERIALS.

\subsection{Antireflection coatings}

Efficient antireflection coatings (ARCs) have been extensively studied and are nowadays well established in industrial applications over large scales (e.g., for photovoltaic, optoelectronic devices, laser windows, and much more). ARC-based multilayered thin films, refractive index gradient, and surface texturing with micro/nanostructures have been optimized with many different methods ${ }^{70}$.

Van de Greop et al. in $2015^{63}$ reported the replicated silica Nano cylinders by conformal contact NIL. The obtained patterns have an effective-index of about 1.20, reducing the double-sided reflection from a glass slide from $7.35 \%$ to $0.57 \%$ (with a minimum reflectance $<0.05 \%$ at $590 \mathrm{~nm}$ ). A nanoimprinted AR coating was applied to Si photovoltaic cells encapsulated in glass. Photovoltaic modules showed a 3.8\% relative increase in short-circuit current, corresponding to a $2.8 \%$ relative increase in power output.

In 2020, Modaresialam et al. ${ }^{62}$ developed the double face printed large-band, broad-angle Antireflection coating on glass by Vapor Pressure Thermal NIL. The hexagonal arrays of nipple-dimple moth eyes nanopillars have an effective refractive index of about 1.2. Total transmission for double-face nanoimprint wafers reached $96-97 \%$ enhancing the transmission of the bare glass of about $90 \%$.

\subsection{Electrodes for batteries}

Recently, the elaboration of the 3D micro-and nano batteries holds great potential in industry to meet the demands of high-power and high energy densities. Until now, several techniques have been reported to elaborate 3D architectures batteries such as thin film deposition on conductive 3D scaffolds, soft templating, direct ink writing, and layer-by-layer (LBL) deposition ${ }^{71-74}$. Today, the compatibility of NIL with the current micro/ nanofabrication process makes technology and high throughput efficient and low cost. 3D microbatteries, made by direct imprinting using crystalline $\mathrm{LiMn}_{2} \mathrm{O}_{4}$ (LMO) nanoparticle-based inks exhibited a power density of about $855.5 \mu \mathrm{Wcm}^{-2} \mu \mathrm{m}^{-1}$, comparable to some of the best micro-supercapacitors ${ }^{54}$. Furthermore, NIL-prepared multi-stacked $\mathrm{TiO}_{2}$ woodpile nanobatteries yield specific capacities as high as $250.9 \mathrm{mAh} \mathrm{g}^{-1}$ with good mechanical strength and stable conductivity performance even over an extended voltage span. As the number of stacked layers increases (see Figure 19), the electrode's areal capacity exhibits a proportional enhancement of potential as (3 to $20 \mu \mathrm{Ah} \mathrm{cm}^{-2}$ for 1 to 6 stacks, respectively $)^{53}$. 

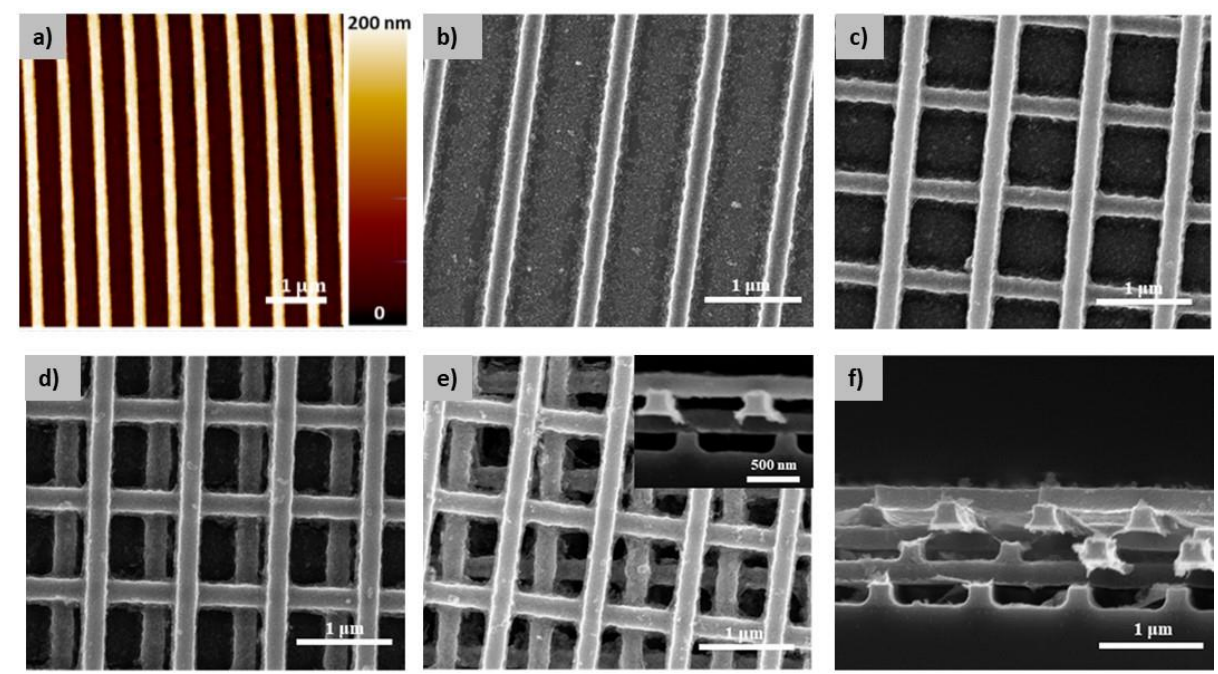

Figure 19. a) AFM height profile of the single-layer imprint. b-f) SEM top view and profile images of imprinted structures corresponding to 1-6 layer(s) woodpile structures ${ }^{53}$. Reprinted with permission from [Li, W.; Zhou, Y.; Howell, I. R.; Gai, Y.; Naik, A. R.; Li, S.; Carter, K. R.; Watkins, J. J. Direct Imprinting of Scalable, High-Performance Woodpile Electrodes for Three-Dimensional Lithium-Ion Nano batteries. ACS Appl. Mater. Interfaces 2018, 10 (6), 5447-5454. https://doi.org/10.1021/acsami.7b14649.], Copyright 2018, ACS- APPLIED MATERIALS \& INTERFACES.

\section{Conclusion}

Optimizing replication in hard inorganic materials by soft-NIL has thus many advantages compared to conventional lithography methods, that lays in its compatibility with a plethora of inorganic material compositions. Such versatility and high throughput characteristics make it ideal for scale-up and production on large surfaces.

Whatever the chosen method of processing, optimizing replications in inorganic material by soft-NIL is a question of adapting the chemistry of the initial solution "resin" and the processing conditions. UV-NIL has been the preferred method for a long time, however, it requires complex chemistry, involving expensive and often toxic photoinitiators. More recently, thermal NIL coupled with pressure or vapor pressure control has been developed, allowing the use of simpler chemistry. For pure inorganic systems, when the final materials need to be organic-free, a final thermal treatment is very often necessary, not only to decompose the organic residues (binders, fluidizers, photo-initiators) but also to mechanically consolidate the edifice by viscous or diffuse sintering. Compromises must be found since this final treatment is accompanied by a more or less pronounced volume shrinkage. Two routes have been explored yet. The first one uses "small" (molecular) dissolved precursors, whereas the second one uses "large" building blocks (nanoparticles) from dispersion. Combinations of the two methods have been explored as composite precursors since they both originate from the same compatible sol-gel chemistry. On one hand, it has been proven that the higher is the concentration of dense nanoparticles, the lower is the shrinkage thanks to highly condensed buildings block. On the other hand, using nanoparticles induces the presence of high surface roughness and residual porosity that may be issued for some applications, but can also be beneficial for others. For instance, on the one hand when the features to reproduce are small, one would prefer using molecular precursors to obtain dense and smooth features. In these cases, one has to adjust the mold feature dimensions to take into account the 
relatively high shrinkage. On the other hand, if porosity is required to facilitate high mass transport of charge transfer, approaches involving nanoparticles, with or without sacrificial binders, are well appropriated.

\section{Acknowledgments}

This material is based on the work supported in part by the National Science Foundation under the International Research Fellowship Program (grant OISE-0505786). The authors also acknowledge funding provided by CNRS, UPMC, and IUF (Institute University of France), the PRCI network ULYSSES (no. ANR-15-CE24-0027-01) funded by the French ANR agency, the A*MIDEX foundation (ANR-11-IDEX0001-02), the A*MIDEX project TITANIDE (no. A-M-AAP-EI-17-58-170228-16.21-ABBARCHI-SAT), and the FET-OPEN project NARCISO (no. 828890). We acknowledge the facilities of the NANOTECMAT platform at the IM2NP Institute. We also thank M. Gibert for providing Figure 1.

\section{References}

(1) Chen, H.-T.; Taylor, A. J.; Yu, N. A Review of Metasurfaces: Physics and Applications. Rep. Prog. Phys. 2016, 79 (7), 076401. https://doi.org/10.1088/0034-4885/79/7/076401.

(2) Jang, D.; Meza, L. R.; Greer, F.; Greer, J. R. Fabrication and Deformation of Three-Dimensional Hollow Ceramic Nanostructures. Nat. Mater. 2013, 12 (10), 893-898. https://doi.org/10.1038/nmat3738.

(3) Schacher, F. H.; Rupar, P. A.; Manners, I. Functional Block Copolymers: Nanostructured Materials with Emerging Applications. Angew. Chem. Int. Ed. 2012, 51 (32), 7898-7921. https://doi.org/10.1002/anie.201200310.

(4) Sanchez, C.; Boissière, C.; Grosso, D.; Laberty, C.; Nicole, L. Design, Synthesis, and Properties of Inorganic and Hybrid Thin Films Having Periodically Organized Nanoporosity ${ }^{\dagger}$. Chem. Mater. 2008, 20 (3), 682-737. https://doi.org/10.1021/cm702100t.

(5) Faustini, M.; Boissière, C.; Nicole, L.; Grosso, D. From Chemical Solutions to Inorganic Nanostructured Materials: A Journey into Evaporation-Driven Processes. Chem. Mater. 2014, 26 (1), 709 723. https://doi.org/10.1021/cm402132y.

(6) Park, C.; Yoon, J.; Thomas, E. L. Enabling Nanotechnology with Self Assembled Block Copolymer Patterns. Polymer 2003, 44 (22), 6725-6760. https://doi.org/10.1016/j.polymer.2003.08.011.

(7) Faustini, M.; Grosso, D. Self-Assembled Inorganic Nanopatterns (INPs) Made by Sol-Gel DipCoating: Applications in Nanotechnology and Nanofabrication. Comptes Rendus Chim. 2016, 19 (1-2), 248-265. https://doi.org/10.1016/j.crci.2015.05.011.

(8) Zheng, C.; Hu, A.; Chen, T.; Oakes, K. D.; Liu, S. Femtosecond Laser Internal Manufacturing of Three-Dimensional Microstructure Devices. Appl. Phys. A 2015, 121 (1), 163-177. https://doi.org/10.1007/s00339-015-9403-x. 
(9) Sugioka, K. Progress in Ultrafast Laser Processing and Future Prospects. Nanophotonics 2017, 6 (2), 393-413. https://doi.org/10.1515/nanoph-2016-0004.

(10) Malinauskas, M.; Žukauskas, A.; Hasegawa, S.; Hayasaki, Y.; Mizeikis, V.; Buividas, R.; Juodkazis, S. Ultrafast Laser Processing of Materials: From Science to Industry. Light Sci. Appl. 2016, 5 (8), e16133-e16133. https://doi.org/10.1038/lsa.2016.133.

(11) Bratton, D.; Yang, D.; Dai, J.; Ober, C. K. Recent Progress in High Resolution Lithography. Polym. Adv. Technol. 2006, 17 (2), 94-103. https://doi.org/10.1002/pat.662.

(12) Chaudhary, R. P.; Jaiswal, A.; Ummethala, G.; Hawal, S. R.; Saxena, S.; Shukla, S. SubWavelength Lithography of Complex 2D and 3D Nanostructures without Two-Photon Dyes. Addit. Manuf. 2017, 16, 30-34. https://doi.org/10.1016/j.addma.2017.05.003.

(13) Totzeck, M.; Ulrich, W.; Göhnermeier, A.; Kaiser, W. Pushing Deep Ultraviolet Lithography to Its Limits. Nat. Photonics 2007, 1 (11), 629-631. https://doi.org/10.1038/nphoton.2007.218.

(14) Bruchhaus, L.; Mazarov, P.; Bischoff, L.; Gierak, J.; Wieck, A. D.; Hövel, H. Comparison of Technologies for Nano Device Prototyping with a Special Focus on Ion Beams: A Review. Appl. Phys. Rev. 2017, 4 (1), 011302. https://doi.org/10.1063/1.4972262.

(15) Liao, Y.-L.; Zhao, Y. Ultra-Narrowband Dielectric Metamaterial Absorber for Sensing Based on Cavity-Coupled Phase Resonance. Results Phys. 2020, 17, 103072. https://doi.org/10.1016/j.rinp.2020.103072.

(16) Stoian, R.; Bhuyan, M. K.; Zhang, G.; Cheng, G.; Meyer, R.; Courvoisier, F. Ultrafast Bessel Beams: Advanced Tools for Laser Materials Processing. Adv. Opt. Technol. 2018, 7 (3), 165-174. https://doi.org/10.1515/aot-2018-0009.

(17) Osellame, R.; Taccheo, S.; Marangoni, M.; Ramponi, R.; Laporta, P.; Polli, D.; De Silvestri, S.; Cerullo, G. Femtosecond Writing of Active Optical Waveguides with Astigmatically Shaped Beams. J. Opt. Soc. Am. B 2003, 20 (7), 1559. https://doi.org/10.1364/JOSAB.20.001559.

(18) Chou, S. Y.; Krauss, P. R.; Renstrom, P. J. Imprint Lithography with 25-Nanometer Resolution. Science 1996, 272 (5258), 85-87. https://doi.org/10.1126/science.272.5258.85.

(19) Heuberger, K.; Lukosz, W. Embossing Technique for Fabricating Surface Relief Gratings on Hard Oxide Waveguides. Appl. Opt. 1986, 25 (9), 1499. https://doi.org/10.1364/AO.25.001499.

(20) Xia, Q.; Yang, J. J.; Wu, W.; Li, X.; Williams, R. S. Self-Aligned Memristor Cross-Point Arrays Fabricated with One Nanoimprint Lithography Step. Nano Lett. 2010, 10 (8), 2909-2914. https://doi.org/10.1021/nl1017157.

(21) Verschuuren, M. A.; Megens, M.; Ni, Y.; van Sprang, H.; Polman, A. Large Area Nanoimprint by Substrate Conformal Imprint Lithography (SCIL). Adv. Opt. Technol. 2017, 6 (3-4). https://doi.org/10.1515/aot-2017-0022.

(22) Delamarche, E.; Schmid, H.; Michel, B.; Biebuyck, H. Stability of Molded Polydimethylsiloxane Microstructures. Adv. Mater. 1997, 9 (9), 741-746. https://doi.org/10.1002/adma.19970090914.

(23) Hui, C. Y.; Jagota, A.; Lin, Y. Y.; Kramer, E. J. Constraints on Microcontact Printing Imposed by Stamp Deformation. Langmuir 2002, 18 (4), 1394-1407. https://doi.org/10.1021/la0113567. 
(24) Schmidt, M. A.; Lei, D. Y.; Wondraczek, L.; Nazabal, V.; Maier, S. A. Hybrid NanoparticleMicrocavity-Based Plasmonic Nanosensors with Improved Detection Resolution and Extended RemoteSensing Ability. Nat. Commun. 2012, 3 (1), 1108. https://doi.org/10.1038/ncomms2109.

(25) Lee, N. Y.; Lim, J. R.; Lee, M. J.; Kim, J. B.; Jo, S. J.; Baik, H. K.; Kim, Y. S. Hydrophilic Composite Elastomeric Mold for High-Resolution Soft Lithography. Langmuir 2006, 22 (21), 9018-9022. https://doi.org/10.1021/la060790b.

(26) Trimbach, D.; Feldman, K.; Spencer, N. D.; Broer, D. J.; Bastiaansen, C. W. M. Block Copolymer Thermoplastic Elastomers for Microcontact Printing. Langmuir 2003, 19 (26), 10957-10961. https://doi.org/10.1021/la035214j.

(27) Peroz, C.; Chauveau, V.; Barthel, E.; Søndergård, E. Nanoimprint Lithography on Silica Sol-Gels: A Simple Route to Sequential Patterning. Adv. Mater. 2009, 21 (5), 555-558. https://doi.org/10.1002/adma.200702484.

(28) Park, H.-H.; Choi, D.-G.; Zhang, X.; Jeon, S.; Park, S.-J.; Lee, S.-W.; Kim, S.; Kim, K.; Choi, J.H.; Lee, J.; Yun, D. K.; Lee, K. J.; Park, H.-H.; Hill, R. H.; Jeong, J.-H. Photo-Induced Hybrid Nanopatterning of Titanium Dioxide via Direct Imprint Lithography. J. Mater. Chem. 2010, 20 (10), 1921. https://doi.org/10.1039/b921343k.

(29) Hlaing, H.; Lu, X.; Nam, C.-Y.; Ocko, B. M. Water-Vapor-Assisted Nanoimprinting of PEDOT:PSS Thin Films. Small 2012, 8 (22), 3443-3447. https://doi.org/10.1002/smll.201201267.

(30) Kothari, R.; Beaulieu, M. R.; Hendricks, N. R.; Li, S.; Watkins, J. J. Direct Patterning of Robust One-Dimensional, Two-Dimensional, and Three-Dimensional Crystalline Metal Oxide Nanostructures Using Imprint Lithography and Nanoparticle Dispersion Inks. Chem. Mater. 2017, 29 (9), 3908-3918. https://doi.org/10.1021/acs.chemmater.6b05398.

(31) Hosokawa, K.; Sato, K.; Ichikawa, N.; Maeda, M. Power-Free Poly(Dimethylsiloxane) Microfluidic Devices for Gold Nanoparticle-Based DNA AnalysisElectronic Supplementary Information (ESI) Available: Sample Movie Used for Flow Characterization, Mathematical Details of the OneDimensional Diffusion Model, and Time Course of the Gold Nanoparticle Deposition. See Http://Www.Rsc.Org/Suppdata/Lc/B4/B403930k/. Lab. Chip 2004, 4 (3), 181. https://doi.org/10.1039/b403930k.

(32) Merkel, T. C.; Bondar, V. I.; Nagai, K.; Freeman, B. D.; Pinnau, I. Gas Sorption, Diffusion, and Permeation in Poly(Dimethylsiloxane).J.Polymer. Sci.: Part B: Polymer Physics, (2000), VOL.(38), 415434

(33) Kim, W.-S.; Yoon, K. B.; Bae, B.-S. Nanopatterning of Photonic Crystals with a Photocurable Silica-Titania Organic-Inorganic Hybrid Material by a UV-Based Nanoimprint Technique. J. Mater. Chem. 2005, 15 (42), 4535. https://doi.org/10.1039/b509622g.

(34) Prosposito, P.; Casalboni, M.; Orsini, E.; Palazzesi, C.; Stella, F. UV-Nanoimprinting Lithography of Bragg Gratings on Hybrid Sol-Gel Based Channel Waveguides. Solid State Sci. 2010, 12 (11), 18861889. https://doi.org/10.1016/j.solidstatesciences.2010.03.014.

(35) Jo, H.-B.; Byeon, K.-J.; Lee, H.; Kwon, M.-H.; Choi, K.-W. Fabrication of ZnO Nano-Structures Using UV Nanoimprint Lithography of a ZnO Nano-Particle Dispersion Resin. J. Mater. Chem. 2012, 22 (38), 20742. https://doi.org/10.1039/c2jm32509h. 
(36) Chong, E.; Kim, S.; Choi, J.-H.; Choi, D.-G.; Jung, J.-Y.; Jeong, J.-H.; Lee, E.; Lee, J.; Park, I.; Lee, J. Interior-Architectured $\mathrm{ZnO}$ Nanostructure for Enhanced Electrical Conductivity via Stepwise Fabrication Process. Nanoscale Res. Lett. 2014, 9 (1), 428. https://doi.org/10.1186/1556-276X-9-428.

(37) Ganesan, R.; Dumond, J.; Saifullah, M. S. M.; Lim, S. H.; Hussain, H.; Low, H. Y. Direct Patterning of $\mathrm{TiO}_{2}$ Using Step-and-Flash Imprint Lithography. ACS Nano 2012, 6 (2), 1494-1502. https://doi.org/10.1021/nn204405k.

(38) Dinachali, S. S.; Saifullah, M. S. M.; Ganesan, R.; Thian, E. S.; He, C. A Universal Scheme for Patterning of Oxides via Thermal Nanoimprint Lithography. Adv. Funct. Mater. 2013, 23 (17), 22012211. https://doi.org/10.1002/adfm.201202577.

(39) Beaulieu, M. R.; Hendricks, N. R.; Watkins, J. J. Large-Area Printing of Optical Gratings and 3D Photonic Crystals Using Solution-Processable Nanoparticle/Polymer Composites. ACS Photonics 2014, 1 (9), 799-805. https://doi.org/10.1021/ph500078f.

(40) Yoon, G.; Kim, K.; Huh, D.; Lee, H.; Rho, J. Single-Step Manufacturing of Hierarchical Dielectric Metalens in the Visible. Nat. Commun. 2020, 11 (1), 2268. https://doi.org/10.1038/s41467-02016136-5.

(41) Dundar Arisoy, F.; Kolewe, K. W.; Homyak, B.; Kurtz, I. S.; Schiffman, J. D.; Watkins, J. J. Bioinspired Photocatalytic Shark-Skin Surfaces with Antibacterial and Antifouling Activity via Nanoimprint Lithography. ACS Appl. Mater. Interfaces 2018, 10 (23), 20055-20063. https://doi.org/10.1021/acsami.8b05066.

(42) Back, F.; Bockmeyer, M.; Rudigier-Voigt, E.; Löbmann, P. Periodic Nanostructures Imprinted on High-Temperature Stable Sol-Gel Films by Ultraviolet-Based Nanoimprint Lithography for Photovoltaic and Photonic Applications. Thin Solid Films 2014, 562, 274-281. https://doi.org/10.1016/j.tsf.2014.04.082.

(43) Battaglia, C.; Escarré, J.; Söderström, K.; Erni, L.; Ding, L.; Bugnon, G.; Billet, A.; Boccard, M.; Barraud, L.; De Wolf, S.; Haug, F.-J.; Despeisse, M.; Ballif, C. Nanoimprint Lithography for HighEfficiency Thin-Film Silicon Solar Cells. Nano Lett. 2011, 11 (2), 661-665. https://doi.org/10.1021/nl1037787.

(44) Battaglia, C.; Escarré, J.; Söderström, K.; Charrière, M.; Despeisse, M.; Haug, F.-J.; Ballif, C. Nanomoulding of Transparent Zinc Oxide Electrodes for Efficient Light Trapping in Solar Cells. Nat. Photonics 2011, 5 (9), 535-538. https://doi.org/10.1038/nphoton.2011.198.

(45) Escarré, J.; Söderström, K.; Battaglia, C.; Haug, F.-J.; Ballif, C. High Fidelity Transfer of Nanometric Random Textures by UV Embossing for Thin Film Solar Cells Applications. Sol. Energy Mater. Sol. Cells 2011, 95 (3), 881-886. https://doi.org/10.1016/j.solmat.2010.11.010.

(46) Kang, M.-G.; Kim, M.-S.; Kim, J.; Guo, L. J. Organic Solar Cells Using Nanoimprinted Transparent Metal Electrodes. Adv. Mater. 2008, 20 (23), 4408-4413. https://doi.org/10.1002/adma.200800750.

(47) Park, I.; Ko, S. H.; Pan, H.; Grigoropoulos, C. P.; Pisano, A. P.; Fréchet, J. M. J.; Lee, E.-S.; Jeong, J.-H. Nanoscale Patterning and Electronics on Flexible Substrate by Direct Nanoimprinting of Metallic Nanoparticles. Adv. Mater. 2008, 20 (3), 489-496. https://doi.org/10.1002/adma.200702326. 
(48) Visser, D.; Chen, D. Y.; Désières, Y.; Ravishankar, A. P.; Anand, S. Embossed Mie Resonator Arrays Composed of Compacted TiO2 Nanoparticles for Broadband Anti-Reflection in Solar Cells. Sci. Rep. 2020, 10 (1), 12527. https://doi.org/10.1038/s41598-020-69518-6.

(49) Zhang, W.; Tu, J.; Long, W.; Lai, W.; Sheng, Y.; Guo, T. Preparation of SiO 2 Anti-Reflection Coatings by Sol-Gel Method. Energy Procedia 2017, 130, 72-76.

https://doi.org/10.1016/j.egypro.2017.09.398.

(50) Letailleur, A.; Teisseire, J.; Chemin, N.; Barthel, E.; Sondergard, E. Chemorheology of Sol-Gel Silica for Patterning High Aspect Ratio Structures by Nanoimprint. Chem. Mater. 2010, 22, 3143-3151, DOI: $10.1021 / \mathrm{cm} 100285 \mathrm{~b}$.

(51) Jiang, W.; Liu, H.; Yin, L.; Ding, Y. Fabrication of Well-Arrayed Plasmonic Mesoporous TiO2/Ag Films for Dye-Sensitized Solar Cells by Multiple-Step Nanoimprint Lithography. J. Mater. Chem. A 2013, 1 (21), 6433. https://doi.org/10.1039/c3ta10882a.

(52) Khan, S. U.; Göbel, O. F.; Blank, D. H. A.; ten Elshof, J. E. Patterning Lead Zirconate Titanate Nanostructures at Sub-200-Nm Resolution by Soft Confocal Imprint Lithography and Nanotransfer Molding. ACS Appl. Mater. Interfaces 2009, 1 (10), 2250-2255. https://doi.org/10.1021/am900417y.

(53) Li, W.; Zhou, Y.; Howell, I. R.; Gai, Y.; Naik, A. R.; Li, S.; Carter, K. R.; Watkins, J. J. Direct Imprinting of Scalable, High-Performance Woodpile Electrodes for Three-Dimensional Lithium-Ion Nanobatteries. ACS Appl. Mater. Interfaces 2018, 10 (6), 5447-5454. https://doi.org/10.1021/acsami.7b14649.

(54) Li, W.; Christiansen, T. L.; Li, C.; Zhou, Y.; Fei, H.; Mamakhel, A.; Iversen, B. B.; Watkins, J. J. High-Power Lithium-Ion Microbatteries from Imprinted 3D Electrodes of Sub-10 Nm LiMn2O4/Li4Ti5O12 Nanocrystals and a Copolymer Gel Electrolyte. Nano Energy 2018, 52, 431-440. https://doi.org/10.1016/j.nanoen.2018.08.019.

(55) Dalstein, O.; Ceratti, D. R.; Boissière, C.; Grosso, D.; Cattoni, A.; Faustini, M. Nanoimprinted, Submicrometric, MOF-Based 2D Photonic Structures: Toward Easy Selective Vapors Sensing by a Smartphone Camera. Adv. Funct. Mater. 2016, 26 (1), 81-90. https://doi.org/10.1002/adfm.201503016.

(56) Faustini, M.; Cattoni, A.; Peron, J.; Boissière, C.; Ebrard, P.; Malchère, A.; Steyer, P.; Grosso, D. Dynamic Shaping of Femtoliter Dew Droplets. ACS Nano 2018, 12 (4), 3243-3252. https://doi.org/10.1021/acsnano.7b07699.

(57) Bottein, T.; Wood, T.; David, T.; Claude, J. B.; Favre, L.; Berbézier, I.; Ronda, A.; Abbarchi, M.; Grosso, D. "Black" Titania Coatings Composed of Sol-Gel Imprinted Mie Resonators Arrays. Adv. Funct. Mater. 2017, 27 (2), 1604924. https://doi.org/10.1002/adfm.201604924.

(58) Chen, H.-L.; Cattoni, A.; De Lépinau, R.; Walker, A. W.; Höhn, O.; Lackner, D.; Siefer, G.; Faustini, M.; Vandamme, N.; Goffard, J.; Behaghel, B.; Dupuis, C.; Bardou, N.; Dimroth, F.; Collin, S. A 19.9\%-Efficient Ultrathin Solar Cell Based on a 205-Nm-Thick GaAs Absorber and a Silver Nanostructured Back Mirror. Nat. Energy 2019, 4 (9), 761-767. https://doi.org/10.1038/s41560-019-0434y.

(59) Bottein, T.; Dalstein, O.; Putero, M.; Cattoni, A.; Faustini, M.; Abbarchi, M.; Grosso, D.

Environment-Controlled Sol-Gel Soft-NIL Processing for Optimized Titania, Alumina, Silica and Yttria- 
Zirconia Imprinting at Sub-Micron Dimensions. Nanoscale 2018, 10 (3), 1420-1431. https://doi.org/10.1039/C7NR07491C.

(60) Naffouti, M.; Backofen, R.; Salvalaglio, M.; Bottein, T.; Lodari, M.; Voigt, A.; David, T.; Benkouider, A.; Fraj, I.; Favre, L.; Ronda, A.; Berbezier, I.; Grosso, D.; Abbarchi, M.; Bollani, M. Complex Dewetting Scenarios of Ultrathin Silicon Films for Large-Scale Nanoarchitectures. Sci. Adv. 2017, 3 (11), eaao1472. https://doi.org/10.1126/sciadv.aao1472.

(61) Checcucci, S.; Bottein, T.; Gurioli, M.; Favre, L.; Grosso, D.; Abbarchi, M. Multifunctional Metasurfaces Based on Direct Nanoimprint of Titania Sol-Gel Coatings. Adv. Opt. Mater. 2019, 1801406. https://doi.org/10.1002/adom.201801406.

(62) Bochet-Modaresialam, M.; Claude, J.-B.; Grosso, D.; Abbarchi, M. Methylated Silica Surfaces Having Tapered Nipple-Dimple Nanopillar Morphologies as Robust Broad-Angle and Broadband Antireflection Coatings. ACS Appl. Nano Mater. 2020, 3 (6), 5231-5239. https://doi.org/10.1021/acsanm.0c00646.

(63) Ferry, V. E.; Verschuuren, M. A.; Lare, M. C. van; Schropp, R. E. I.; Atwater, H. A.; Polman, A. Optimized Spatial Correlations for Broadband Light Trapping Nanopatterns in High Efficiency Ultrathin Film A-Si:H Solar Cells. Nano Lett. 2011, 11 (10), 4239-4245. https://doi.org/10.1021/nl202226r.

(64) Shin, S.-H.; Choi, S.-Y.; Lee, M. H.; Nah, J. High-Performance Piezoelectric Nanogenerators via Imprinted Sol-Gel BaTiO 3 Nanopillar Array. ACS Appl. Mater. Interfaces 2017, 9 (47), 41099-41103. https://doi.org/10.1021/acsami.7b11773.

(65) Kim, K.-C. Effective Graded Refractive-Index Anti-Reflection Coating for High Refractive-Index Polymer Ophthalmic Lenses. Mater. Lett. 2015, 160, 158-161.

https://doi.org/10.1016/j.matlet.2015.07.108.

(66) van de Groep, J.; Spinelli, P.; Polman, A. Single-Step Soft-Imprinted Large-Area Nanopatterned Antireflection Coating. Nano Lett. 2015, 15 (6), 4223-4228. https://doi.org/10.1021/acs.nanolett.5b01623.

(67) van Lare, C.; Yin, G.; Polman, A.; Schmid, M. Light Coupling and Trapping in Ultrathin $\mathrm{Cu}(\mathrm{In}, \mathrm{Ga}) \mathrm{Se}_{2}$ Solar Cells Using Dielectric Scattering Patterns. ACS Nano 2015, 9 (10), 9603-9613. https://doi.org/10.1021/acsnano.5b04091.

(68) Knight, M. W.; van de Groep, J.; Bronsveld, P. C. P.; Sinke, W. C.; Polman, A. Soft Imprinted Ag Nanowire Hybrid Electrodes on Silicon Heterojunction Solar Cells. Nano Energy 2016, 30, 398-406. https://doi.org/10.1016/j.nanoen.2016.10.011.

(69) van de Groep, J.; Gupta, D.; Verschuuren, M. A.; M. Wienk, M.; Janssen, R. A. J.; Polman, A. Large-Area Soft-Imprinted Nanowire Networks as Light Trapping Transparent Conductors. Sci. Rep. 2015, 5 (1), 11414. https://doi.org/10.1038/srep11414.

(70) Raut, H. K.; Ganesh, V. A.; Nair, A. S.; Ramakrishna, S. Anti-Reflective Coatings: A Critical, inDepth Review. Energy Environ. Sci. 2011, 4 (10), 3779. https://doi.org/10.1039/c1ee01297e.

(71) Dokko, K.; Sugaya, J.; Nakano, H.; Yasukawa, T.; Matsue, T.; Kanamura, K. Sol-Gel Fabrication of Lithium-Ion Microarray Battery. Electrochem. Commun. 2007, 6.

(72) Zhang, H.; Yu, X.; Braun, P. V. Three-Dimensional Bicontinuous Ultrafast-Charge and Discharge Bulk Battery Electrodes. Nat. Nanotechnol. 2011, 6, 5. 
(73) Cheah, S. K.; Perre, E.; Rooth, M.; Fondell, M.; Hårsta, A.; Nyholm, L.; Boman, M.; Simon, P. Self-Supported Three-Dimensional Nanoelectrodes for Microbattery Applications. Nano Lett 2009, 9 (9), 4.

(74) Létiche, M.; Eustache, E.; Freixas, J.; Demortière, A.; Andrade, V. D.; Morgenroth, L.; Tilmant, P.; Vaurette, F.; Troadec, D.; Roussel, P.; Brousse, T.; Lethien, C. Atomic Layer Deposition of Functional Layers for on Chip 3D Li-Ion All Solid State Microbattery. Adv Energy Mater 2017, 12.

\section{Table of Content}

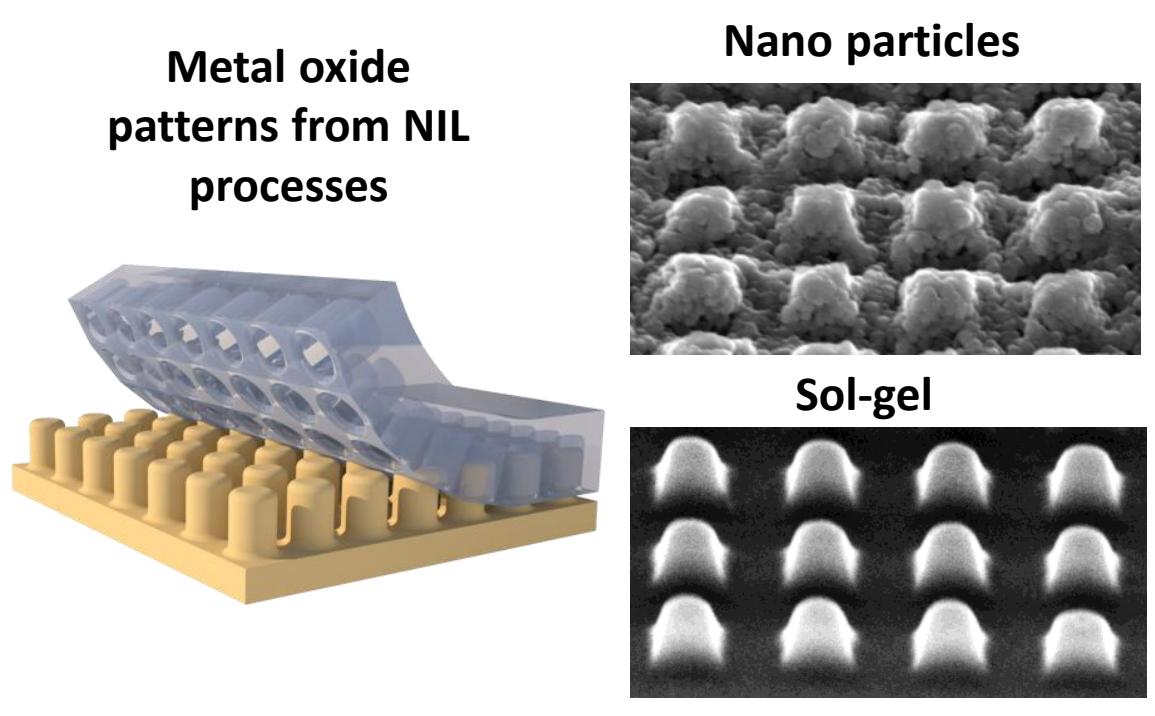

